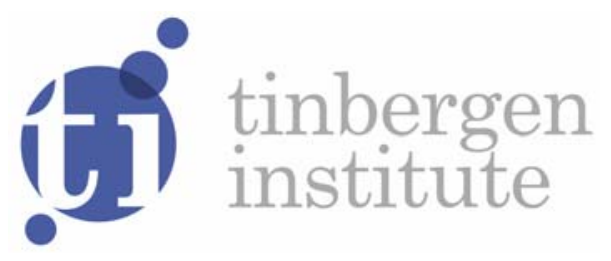

\title{
International Trade and Labor Market Discrimination
}

Richard Chisik'

Julian Emami Namini2

${ }^{\prime}$ Ryerson University, Toronto, Canada;

2 Erasmus School of Economics, Erasmus University Rotterdam, and Tinbergen Institute, the Netherlands. 
Tinbergen Institute is the graduate school and research institute in economics of Erasmus University Rotterdam, the University of Amsterdam and VU University Amsterdam.

More TI discussion papers can be downloaded at http://www.tinbergen.nl

Tinbergen Institute has two locations:

Tinbergen Institute Amsterdam

Gustav Mahlerplein 117

1082 MS Amsterdam

The Netherlands

Tel.: +31(0)20525 1600

Tinbergen Institute Rotterdam

Burg. Oudlaan 50

3062 PA Rotterdam

The Netherlands

Tel.: +31(0)10 4088900

Fax: +31(0)10 4089031 


\title{
International Trade and Labor Market Discrimination
}

\author{
Richard Chisik $^{*}$ and Julian Emami Namini ${ }^{\dagger}$
}

December 9, 2016

\begin{abstract}
We embed a competitive search model with labor market discrimination into a two-sector, two-country framework in order to analyze how labor market discrimination impacts the pattern of international trade and also how trade affects discrimination. Discrimination reduces the matching probability and output in the skilled-labor intensive differentiated-product sector so that the country with more discriminatory firms has a comparative advantage in the simple sector. As countries alter their production mix in accordance with their comparative advantage, trade liberalization can then reinforce the negative effect of discrimination on development in the more discriminatory country and reduce its effect in the country with fewer discriminatory firms. Similarly, as a result of globalization, the profit difference between non-discriminatory and discriminatory firms increases in the less discriminatory country and diminishes in the more discriminatory one. In this way trade can further reduce discrimination in a country where it is less prevalent and increase it where it is more firmly entrenched.
\end{abstract}

JELClassification: F16, F66, J71

Keywords: Discrimination, International Trade, Competitive Search

${ }^{*}$ Department of Economics, JOR-211, Ryerson University, Toronto, ON, M5B 2K3. E-mail: rchisik@arts.ryerson.edu. Phone: +1-416-979-5000 Ext. 4620.

${ }^{\dagger}$ Erasmus School of Economics, Erasmus University Rotterdam, P.O. Box 1738, 3000DR Rotterdam, the Netherlands, Tinbergen Institute, and Centro Studi Luca d'Agliano. E-mail: emaminamini@ese.eur.nl. Phone: +31-10-408-1399. 


\section{Introduction}

In Gary Becker's (1957) seminal work on labor market discrimination he suggests that discrimination is costly to the firms that practice it. In a similar way that a discriminator has to pay for his taste to exclude certain groups, a nepotist will incur a cost when he excludes non-relatives. ${ }^{1}$ If practicing discrimination, or nepotism, reduces the relative productivity of a firm within a country, then it seems possible that a country where discrimination or nepotism is more prevalent may have lower relative productivity in sectors where exclusion is more costly. In this paper we analyze this question to determine if some forms of labor market discrimination can be a source of comparative advantage. We then return to Becker's original idea and ask whether the pro-competitive effects of international trade can mitigate discrimination.

The effect of discrimination on aggregate productivity and growth has received recent attention. For example, Hsieh, Hurst, Jones, and Klenow (2013) show that between fifteen and twenty percent of the growth in US output per worker between 1960 and 2008 can be explained by allowing blacks and white women into skilled occupations in which they were formerly very poorly represented. The negative effect of the gender wage gap on growth has also been demonstrated by Galor and Weil (1996), Lagerlöf (2003), Esteve-Volart (2009), Cuberes and Teignier (2014), and Cavalcanti and Tavares (2016). ${ }^{2}$ The effect of nepotism on economic performance in southern European countries has been studied by Bloom and Van Reenen (2007). We depart from these previous studies by considering the effect of discrimination on the pattern of trade as well as the converse effect of trade liberalization on discrimination.

We take as given that some forms of labor market discrimination exist and ask how does this discrimination affect the structure of the economy. ${ }^{3}$ A very nice overview of the literature on discrimination is provided by Lang and Lehman (2012), who discuss an overwhelming number

\footnotetext{
${ }^{1}$ In fact, Bloom and Van Reenen (2007) show that much of the long tail of very-poorly managed firms can be explained by primogeniture.

${ }^{2}$ An interesting anecdotal example is provided by India. It is a democracy that does not suffer from a natural resource curse and it has a large well-educated English-speaking population, but is still plagued by low labor productivity. A partial explanation may be found in the fact that twenty-five percent of India's population belongs to the scheduled (formerly backward) castes and tribes (i.e. the untouchables) and over thirteen percent of India's population is Muslim. Thus, more than thirty-eight percent of India's population has historically suffered restricted access to the Indian formal labor market.

${ }^{3}$ As Gary Becker noted about his (1957) book "For several years it had no visible impact on anything. Most economists did not think racial discrimination was economics, and sociologists and psychologists generally did not believe I was contributing to their fields," as quoted in Murphy (2014). The eventual realization that discrimination is an important topic for economists is echoed in the words of Kevin Murphy (2014), "Now the impact is clear. Not only is racial discrimination viewed as a subject about which economics has something useful to say, but economists are among the top academics in any field researching the topic."
} 
of papers that cannot reject the empirical evidence on labor-market discrimination. Fang and Moro (2010) contains a review of many additional theoretical papers on discrimination that are not covered in Lang and Lehman (2012).

To this end, we embed a directed (competitive) search model into a general equilibrium framework. There are two sectors in the economy: a simple sector that uses only labor and a sector in which each firm produces a differentiated product using labor and a manager. Firms in this second sector can only produce if they successfully hire a manager. In order to locate a manager, firms post a payment for the manager and the skilled workers decide where to apply (unskilled workers cannot become managers). Any skilled worker who does not find a match as a manager can work with the unskilled workers as labor in either sector. As we restrict entry into the differentiated product sector, firms in this sector realize profits. The gross profits include a bonus that is payment to the manager and the remaining net profits are shared equally by all agents.

Our modeling of discrimination in a competitive search environment follows Lang, Manove and Dickens (2005), henceforth LMD. ${ }^{4}$ We start by assuming that all firm $P$ efer to a hire a manager of a certain label. That is, productivity of either label of skilled worker is the same, but every firm has a very slight preference for an $A$-label over a $B$-label manager. Labels may refer to differences in skin color, eye color, gender, religion, caste, ancestral origin, native language, regional accent, or familial connections. This preference only matters if skilled workers of both labels apply to the same firm. In that case a firm would always hire an A-label manager and they would hire a $B$-label only if no $A$-labels apply. This firm preference implies that in equilibrium no $B$-labels will apply to a firm that attracts A-labels and vice-versa. Hence, there are two posted payments in equilibrium: a higher one by firms that attract $A$-labels and a lower one by those that attract $B$-labels. Because the two groups are divided, which increases oligopsonistic power of firms in the labor market, both posted payments are lower than in the label-blind equilibrium (i.e. in the equilibrium without discrimination). Furthermore, because the posted payments are different, the portion of firms posting each payment differs from the proportion of each label in the population. ${ }^{5}$

\footnotetext{
${ }^{4}$ In particular we take their one-good model and extend it to a monopolistically-competitive two sector framework. Our more important extensions is the inclusion of non-discriminatory firms and also international trade. Although the first seven of our fifteen results are an extension of theirs to our general equilibrium framework, we fully present all results and propositions without referring the reader to their paper for two reasons. First, intimate familiarity with these first results is necessary in order for the reader to understand our extensions, which are the inclusion of some non-discriminatory firms, a general equilibrium environment, and international trade. Second, we provide additional figures that not only illustrate our extensions but also help clarify their original model.

${ }^{5}$ As a result of the lower payment and, therefore, more profits per successful match, more firms will post a payment to attract a $B$-label manager than those that post to attract an $A$-label manager.
} 
There is then an asymmetric arrival rate at the two groups of firms and, consequently, the overall arrival rate of potential managers at firms is lower than in the label-blind equilibrium. Hence, the matching rate is lower in the discriminatory equilibrium.

The lower match success rate implies fewer varieties of the aggregate differentiated product and a higher relative autarky price of this product for a country in a discriminatory equilibrium. Hence, when liberalizing trade with a label-blind country, the discriminatory country will be an exporter of the simple good that does not require a manager or a skilled worker. It is through the induced distortion in the matching process that discrimination inhibits development of the differentiated product sector and generates comparative advantage in the simple sector. The country in a labelblind equilibrium has more varieties per worker and, therefore, realized profits of a successful firm (i.e. of a firm that has found a manager) in the label-blind country increase when they liberalize trade. Output per successful firm, output for the entire differentiated product sector, and the payment to each hired manager also rises in the label-blind country as a result of trade liberalization. In the discriminatory country trade liberalization has the opposite effect on profit, output, and managerial remuneration.

In order to consider the effect of trade on discrimination we introduce a second type of firm. These firms are label-blind and it is common knowledge that they do not discriminate. Because they are known to not show hiring preference to either label of manager, they can offer a higher payment to $B$-label managers than can the existing discriminatory firms. This higher payment by a discriminatory firm would attract $A$-labels because they would be hired with certainty, however, they would only be hired with an equal probability by the non-discriminatory firms. The presence of these non-discriminatory firms partially mitigates the discrimination induced matching inefficiencies in the resulting equilibrium. In addition, these firms have higher expected profits than the discriminatory firms because they have a higher matching probability. ${ }^{6}$

Finally, we consider trade between two countries that differ in their percentage share of nondiscriminatory firms in the firm distribution. Our previous result on comparative advantage translates to this extended version of our model. In particular, the country with relatively more discriminatory firms has a comparative advantage in the simple sector. For the country with more

\footnotetext{
${ }^{6}$ If entry were costless, then these firms would come to dominate the market which would substantiate the hypothesis first mentioned in Becker (1957) and substantiated in Arrow (1972). Alternatively, if firms had to pay an entry cost and if firms had differing entry costs (or differing variable costs), then non-discriminatory firms would be able to enter for a higher entry (or variable) cost, but they would not take over the market. As our focus is on how trade affects each type of firm, we limi tir numbers and instead analyze how the relative profits of discriminatory and non-discriminatory firms are effected by trade.
} 
label-blind firms, output per successful firm, output of the differentiated product sector, the realized profits of a successful firm, and the payment to each manager all increase when liberalizing trade and the opposite happens in the country with more discriminatory firms. Because the expected profits of a label-blind firm are greater than those of a discriminatory firm, they see a bigger change as a result of opening to trade. In particular, because of their higher match probability, any change in realized firm profit has a magnified effect on their expected profit. For the country with less discrimination, trade liberalization increases the label-blind firms' expected profits by more than those of the discriminatory firms. In the country with more discrimination, trade liberalization reduces the profits of the label-blind firms by a larger amount. Hence, trade liberalization can help to reduce discrimination in the country where it is less prevalent and enhance it in the country where it is more widespread.

Our paper is related to several distinct strands of the literature.

We contribute to the research mentioned above that relates discrimination (or nepotism) to growth by considering its effect on the pattern of trade and the converse effect of trade on discrimination. Starting with Black (1995) and Rosen $(1997,2003)$, economists have analyzed discrimination as the equilibrium of a model with random search. Recognizing that firms may want to strategically post a payment, LMD analyze discrimination as the equilibrium of a competitive search framework. We extend this literature by adding some additional non-discriminatory firms to the framework of LMD, embedding it into a two-sector general equilibrium environment, and allowing for international trade. Finally, our paper is related to the broad literature on international trade with labor market frictions, such as Davidson, Martin and Matusz (1999), Davidson, Matusz and Shevchenko (2008), Helpman and Itskhoki (2010), Helpman, Itskhoki and Redding (2010), Ranjan (2013), and Grossman, Helpman and Kircher (2013). We extend this literature in three ways. First, we analyze a competitive instead of a random search framework. Second, we analyze discrimination as a source of comparative advantage. Third we analyze how trade liberalization affects the prevalence of discrimination.

In the next section we describe our basic framework. In the third section we consider autarky with and without discrimination. International trade is considered in the fourth section. In the fifth section we introduce non-discriminatory firms and we analyze trade in this extended framework in the sixth section. Our conclusions are contained in the seventh section. 


\section{Economic environment}

There are two countries: Home and Foreign. We denote foreign variables with an $\left(^{*}\right)$. In each country there are two sectors. The numeraire sector produces perfectly substitutable goods with a constant returns to scale technology using only labor. The monopolistically competitive sector produces differentiated goods using labor and a manager. Upper tier preferences over goods from the two sectors can be represented by a Cobb-Douglas utility function:

$$
U\left(C_{M}, C_{0}\right)=C_{M}^{\alpha} C_{0}^{1-\alpha}
$$

Preferences over the manufactured goods in the monopolistically competitive sector can be represented by a constant elasticity of substitution sub-utility function:

$$
C_{M}=\left(\sum_{z=0}^{\infty} c_{z}{ }^{\frac{\sigma-1}{\sigma}}\right)^{\frac{\sigma}{\sigma-1}}
$$

where the elasticity of substitution between varieties is $\sigma$ and $\sigma>1$. Therefore, none of these varieties is essential to consumption. Although preferences are defined over a potentially infinite number of varieties, only a finite number will be available to consume. Agents derive income from working as either labor, or if they are skilled and successfully locate a match, as a manager. In addition, all agents are equal owners of each of the firms and they equally share any firm profits. Each firm producing in the monopolistically competitive sector has the same technology:

$$
\ell_{z}=\left\{\begin{array}{cc}
q_{z}+f & \text { if } m_{z}=1 \\
\xi & \text { if } m_{z}=0
\end{array},\right.
$$

where $\ell_{z}$ is the amount of labor used in producing good $z, q_{z}$ is the quantity of variety $z, m_{z}$ is a manager for the firm producing good $z, f$ denotes the fixed input requirement, and $\xi$ is an arbitrary large constant that makes production unfeasible if firm $z$ is not successful in hiring a manager, i.e. if $m_{z}=0$. We use the convention that all fixed costs are paid in terms of labor.

The technology for producing the numeraire good is $\ell_{0}=q_{0}$, and the labor supply of each country, $L=L^{*}$, is assumed to be large enough so that there is positive numeraire production in each

country and the wage of unskilled workers in either sector is, therefore, equal to the price of the 
numeraire good, $P_{0}$, which is one in equilibrium. Although equal to unity, we still include $P_{0}$ in several equations to help the reader more easiny follow the analysis.

We are interested in the composition of firms in the monopolistically competitive sector rather than their absolute number, therefore, the number of potentially active firms in the monopolistically competitive sector, $N=N^{*}$, is taken as exogenous. As a result of search frictions only $M$ of the $N\left(M^{*}\right.$ of the $\left.N^{*}\right)$ firms are successful in hiring a manager and producing. ${ }^{7}$ Still, the size of the economy is large enough so that the number of operating manufacturing firms is large and, therefore, the effect of each manufacturing firm's output on the price and quantity of other firms is negligible.

For each home firm that successfully hires a manager, the product market is described by monopolistic competition. As shown by Dixit and Stiglitz (1977), the set of purchased manufactured goods can be considered as a composite good $C_{M}$ with corresponding aggregate price

$$
P_{M}=\left(\sum_{z \in M} p_{z}^{1-\sigma}\right)^{\frac{1}{1-\sigma}}
$$

Consumer maximization of the first stage utility function yields the following demand functions:

$$
C_{M}=\frac{\alpha I}{P_{M}} ; \quad C_{0}=\frac{(1-\alpha) I}{P_{0}} ;
$$

where $I$ denotes aggregate income which we will derive below. Consumer maximization of the sub-utility function yields demand for each variety as

$$
c_{z}=C_{M}\left(\frac{p_{z}}{P_{M}}\right)^{-\sigma} \text {. }
$$

Each manufacturing firm chooses output to maximize profits, taking the output of other firms and the aggregate price index and $C_{M}$ as given. This leads to the following pricing rule: $p_{z}=\frac{\sigma}{\sigma-1}$. Hence,

$$
c_{z}=\frac{\alpha I}{M p_{z}}=\frac{\alpha I}{M \frac{\sigma}{\sigma-1}},
$$

\footnotetext{
${ }^{7}$ Although $N=N^{*}$, it is not necessarily the case that $M=M^{*}$.
} 
and, denoting firm revenue as $r_{z}$, the gross profits of operating each firm is given by:

$$
\pi_{z}=r_{z}-l_{z}=p_{z} q_{z}-q_{z}-f=p_{z} q_{z}-q_{z} p_{z} \frac{\sigma-1}{\sigma}-f=\frac{r_{z}}{\sigma}-f=\frac{\alpha I}{M \sigma}-f
$$

Agents in each country are either skilled or unskilled. Unskilled ones work either in the numeraire sector or as laborers in the manufacturing sector. Skilled workers can work as a manager if they are offered a managerial job and they can also work as unskilled labor if their managerial search is unsuccessful.

In addition to their skill level (skilled versus unskilled), agents differ by their label $k \in\{A, B\}$. Labels may refer to differences in skin color, eye color, gender, religion, caste, ancestral origin, native language, regional accent, or familial connections. This label is also perfectly observable and it is common knowledge that productivity does not depend on the label. The number of skilled workers in each country with each label is given as $S_{k}=S_{k}^{*}$. The total number of unskilled workers in the home country is, therefore, $L-S_{A}-S_{B}=L-S$. Only a subset $M$ of the $S$ will find work as a manager and the remainder will work as laborers in either sector.

Despite the identical productivity of all skilled workers, firms may prefer to hire an A-label manager. Formally, the preferences of firms are lexicographic: first firms prefer to hire a manager, second they prefer to hire an $A$-label manager. (An alternative, but theoretically equivalent formulation is that there is a vanishingly small disutility for a home firm that hires a $B$-label manager.) Hence, if skilled managers of each label apply to the same job with the same posted bonus, then the firm will hire the A-label worker. A $B$-label manager will be hired by a firm only if there are no A-label skilled applicants at the posted bonus. We use the term bonus for the payment to managers in order to differentiate it from the payment to labor, which is the wage. Finally we denote the portion of $B$-label skilled workers in each country as $\beta$ so that the number of $A$-label skilled workers is $S_{A}=(1-\beta) S$. We assume that $\beta \in(0,1)$. At times we will find it useful to write $\beta_{B}=\beta$ and $\beta_{A}=1-\beta$ or, more generally, $\beta_{k}$. Firms have no preferences over the label of unskilled workers.

The timing and information structure of the model is as follows. We write the case of the home country. The foreign country is similar. First, each of the $N$ firms posts a bonus, $b_{z}$, for a manager. Second, skilled workers observe the vector of posted bonuses, $\mathbf{b}=\left\{b_{z}\right\}$, and decide where to apply. Skilled workers can only apply once and to only one firm. ${ }^{8}$ Formally, from the perspective

\footnotetext{
${ }^{8}$ As long as there is some cost to additional applications, allowing skilled workers to apply to more than one firm
} 
of firms a worker's action at this stage is a collection of probabilities that they will apply to firm $z$, denoted as $a_{z}(\mathbf{b})$. The skilled worker's strategy is restricted to those that assign equal probability to all firms offering the same bonus. Hence, the workers' strategies satisfy anonymity. Third, the $M$ firms that have an applicant are successful and produce and sell their goods in the market. Unsuccessful firms do not produce. Unmatched skilled workers and all unskilled workers work as wage laborers in the manufacturing or numeraire sector.

Firm $z$ 's strategy consists of posting a bonus and choosing output. Each agent's strategy is a vector of application probabilities $\mathbf{a}(\mathbf{b})=\left\{a_{z}(\mathbf{b})\right\}$. If all skilled workers with the same label use the same strategy, then the expected number of workers of each label applying to firm $z$ is given by $\lambda_{z k}=a_{z}(\mathbf{b}) S_{k}$. Note that, because the application probabilities sum to one, we have that the market tightness $S$ / $N$ for each label can be expressed as $\frac{1}{N} \sum \lambda_{z k}=\beta_{k} S / N$. Since the firms' and the skilled workers' payoff functions depend on whether or not firms discriminate across workers, we will derive the payoff functions in the corresponding sections.

In the next section we analyze autarky first for an economy where no firms discriminate and then for one where all firms discriminate. Other than the extension to general equilibrium and the introduction of our figure 2, much of the analysis in this section is similar to that in LMD. We include a full description of the model here because understanding these first seven results is necessary for understanding our extensions to international trade and to the introduction of non-discriminatory firms. These extensions are then analyzed in results eight through fifteen.

\section{The closed economy}

\subsection{Autarky without discrimination}

We start with the case of no discrimination and with a closed economy, therefore, we can suppress the subscript $k$ in this section. We will be interested in the limiting case when $N$ and $S$ become very large but their ratio $\theta$ is still finite. A manufacturing firm will only be able to produce if it hires a manager. This occurs if and only if it receives at least one applicant. The probability it receives at least one applicant is $1-\left(1-a_{z}\right)^{S}$. When $S$ and $N$ are large this converges to

$$
1-\operatorname{Pr}\left(\lambda_{z}=0\right)=1-\left(1-a_{z}\right)^{S} \rightarrow 1-e^{-a_{z} S}=1-e^{-\lambda_{z}} .
$$

would not have any qualitative effect on our results. 
A firm's expected profit net of payment to a manager is:

$$
E\left(\pi_{z}^{n e t}\right)=\left(1-e^{-\lambda_{z}}\right)\left(\pi_{z}-b_{z}\right)
$$

where $b_{z}$ denotes the bonus to the manager. The equilibrium level of $b_{z}$, which maximizes $E\left(\pi_{z}^{n e t}\right)$, will be derived below.

The probability that an applicant is hired at a firm $z$ is the product of the probability that there is at least one applicant times the probability that they are the chosen one. Hence, the probability (from the perspective of an applicant) that they are hired at a single firm $z$ is:

$$
\operatorname{Pr}(\text { hired })=h\left(\lambda_{z}\right)=\frac{1-\left(1-a_{z}\right)^{S}}{a_{z} S} \rightarrow \frac{1-e^{-\lambda_{z}}}{\lambda_{z}}
$$

Thus, a skilled worker's expected bonus if they apply to a firm $z$ is given by $V_{z}=b_{z} h\left(\lambda_{z}\right)$. We assume that that the total labor supply, $L$, is sufficiently large compared to the skilled labor supply, $S$, so that the expected bonus is larger than the wage, which is one, so that all skilled workers apply for a managerial position. The necessary condition on $L$ and $S$ is derived in the proofs of propositions 1 and 3 .

We now consider a sub-game perfect monopolistically competitive equilibrium (SPMCE), which is characterized as follows:

1. Each firm's $b_{z}$ is a best response to the vectors of firm's and skilled worker's strategies, $\mathbf{b}$ and $\mathbf{a}$.

2. Each skilled worker's $a(\mathbf{b})$ is a best response to $\mathbf{b}$ and to $\mathbf{a}(\mathbf{b})$ of all other workers.

3. Each firm chooses $q_{z}$ to maximize $\pi_{z}$.

4. Each agent chooses $C_{0}$ and the amount $c_{z}$ consumed of each variety of $C_{M}$ to maximize utility subject to the budget constraint and given prices $P_{M}$ and $p_{z}$.

5. Relative supply of the $M$ manufactured goods and of the numeraire good equals relative demand for these goods and the labor market clears.

Note that the large number of firms, skilled workers, and consumers ensures that $\mathbf{b}, \mathbf{a}, C_{M}$ and $P_{M}$ are neither sensitive to a firm's own bonus and quantity choice nor to a skilled worker's choice or a consumer's choice. 
We solve for the SPMCE of this game by backwards induction and we start by showing that the skilled workers' application subgame has a unique symmetric equilibrium for each given vector of bonus offers b. "Symmetric" refers to an equilibrium in which each skilled worker chooses the same application strategy. We use the subscript $U$ to refer to the benchmark unbiased equilibrium without discrimination. The following proposition describes the unbiased equilibrium.

Proposition 1. There exists a unique symmetric SPMCE in which all firms offer an identical bonus $b_{U}=$ $\frac{\pi_{U} \lambda_{U}}{e^{\lambda} U-1}$ and all skilled workers adopt the same mixed application strategy in which they apply at each single firm with the same probability. A single skilled worker's expected bonus is given by $V_{U}=\pi_{U} e^{-\lambda_{U}}$, profits

of each operating firm result as $\pi_{U}=\frac{1}{\sigma-\alpha}\left(\alpha\left[\frac{L}{N\left(1-e^{-\lambda} U\right.}-1\right]-\sigma f\right)$ and expected profits of each firm net of bonus payments are given by $E\left(\pi_{U}^{n e t}\right)=\left[1-\left(1+\lambda_{U}\right) e^{-\lambda_{U}}\right] \pi_{U}$. National income results as $I_{U}=$ $\frac{\sigma}{\sigma-\alpha}\left[L-(1+f) M_{U}\right]$ and the number of operating firms is given by $M_{U}=S \frac{1-e^{-\lambda_{U}}}{\lambda_{U}}=N\left(1-e^{-\lambda_{U}}\right)$.

The proof of proposition 1 is in the appendix. The idea of the proof is as follows. Skilled workers only apply at firms offering the highest bonus, therefore, all firms offer the same bonus in equilibrium. Rearranging the expression for the expected bonus we have that $b_{z}=V_{z} / h\left(\lambda_{z}\right)$. Substituting this expression along with the probability of being hired (from equation 11) into the firms expected net profit (from equation 10) allows us to consider the firms as choosing the optimal expected number of applicants instead of the optimal bonus.

\subsection{Autarky with discrimination}

We now consider two labels of skilled workers, $A$ and $B$. In this section all firms prefer to hire an $A$-label manager if given the choice. We use the subscripts $A$ and $B$ for variables pertaining to either label and the subscript $D$ for aggregate values in the discriminatory equilibrium.

Firms can only post a single bonus (it is illegal to post label-dependent wages in most countries) and skilled workers can apply at most to only one firm. The skilled workers' strategies again satisfy anonymity. A firm that attracts at least one applicant at its posted wage will successfully hire a manager. If a single firm has more than one applicant of the same label, then it will choose randomly among those applicants, however, if it has applicants from both labels, then it will always hire an A-label. As mentioned above, firms' preferences are lexicographic. They prefer to have a match, and given a match, they prefer an A-label manager. 
The case for A-label skilled workers is similar to the previous section. Of course, the number of all skilled workers combined, $S$, is greater than the number of $A$-labels, $S_{A}$. Furthermore, the application strategies for the $A$-labels, $a_{A}$, will also differ from the probabilities, $a_{z}=1 / N$, as given in the previous section. The more interesting case is that of the $B$-labels. In the following lemma we show that any bonus that is large enough to attract $A$-labels would discourage $B$-labels from applying (because they know that an A-label would always be shown preference).

Lemma 2. In any symmetric SPMCE firms separate so that a firm either chooses a bonus that attracts only A-label applicants or only B-label applicants, but not both.

The proof of lemma 2 is in the appendix. The intuition is that any bonus that attracts both labels could be improved upon by one that is slightly lower and that attracts many more $B$-labels while only losing the few A-label applicants. The result is that some firms post a lower bonus and only expect to attract $B$-labels and others post a larger one to attract only $A$-labels.

Denote by $N_{A}$ and $N_{B}$ the numbers of $A$ - and $B$-label attracting firms. In equilibrium the expected net profits of each firm must be the same. Note also that $\lambda_{A}=\frac{S_{A}}{N_{A}}$ and $\lambda_{B}=\frac{S_{B}}{N_{B}}$ are the expected numbers of applicants to firms in each group. We can now derive the equilibrium bonuses, expected profits and expected income for each type of firm and label of worker. Note that $b_{A}\left(b_{B}\right)$ are the bonuses that attract only $A$-label (only $B$-label) skilled workers and $\pi_{D}$ is the realized profits in the discriminatory equilibrium. This leads us to proposition 3.

Proposition 3. In any symmetric SPMCE with discrimination we have: (i) $b_{A}=\frac{\pi_{A} \lambda_{A}}{e^{\lambda_{A}-1}}, V_{A}(\mathbf{b})=\pi_{D} e^{-\lambda_{A}}$ and $E\left(\pi_{A}^{n e t}\right)=\left[1-\left(1+\lambda_{A}\right) e^{-\lambda_{A}}\right] \pi_{D}$; (ii) $\pi_{D}=\frac{1}{\sigma-\alpha}\left(\alpha\left[\frac{L}{M_{D}}-1\right]-\sigma f\right)$, where $M_{D}=S_{B} \frac{1-e^{-\lambda_{B}}}{\lambda_{B}}+$ $S_{A} \frac{1-e^{-\lambda_{A}}}{\lambda_{A}} ;$ (iii) $b_{B}=V_{A}(\mathbf{b}), V_{B}(\mathbf{b})=\pi_{D} e^{-\lambda_{A}} \frac{1-e^{-\lambda_{B}}}{\lambda_{B}}$ and $E\left(\pi_{B}^{n e t}\right)=\left(1-e^{-\lambda_{B}}\right)\left(1-e^{-\lambda_{A}}\right) \pi_{D}$;

(iv) $I_{D}=\frac{\sigma}{\sigma-\alpha}\left[L-(1+f) M_{D}\right]$.

The proof to proposition 3 is in the appendix. The derivation of the expressions for the A-labels is similar to those in proposition 1 . For the $B$-labels note that for any bonus that attracts $B$-label applicants we must have $b_{B} \leq V_{A}$ (b) because an $A$-label would apply (and be hired with certainty) if $b_{B}>V_{A}(\mathbf{b})$. Hence, $b_{B}=V_{A}(\mathbf{b})$ and then $V_{B}(\mathbf{b})=V_{A}(\mathbf{b}) h\left(\lambda_{B}\right)$.

We now define $\eta \equiv \frac{N_{A}}{N}$ and we note that $\lambda_{U}=\eta \lambda_{A}+(1-\eta) \lambda_{B}=\frac{S}{N}$. We use this notation to show that there is a unique autarkic equilibrium with discrimination and we then consider comparative statics with respect to the portion of $B$-labels and the number of firms. 
Proposition 4. There is a unique symmetric SPMCE of this competitive search wage posting game with discrimination. In this equilibrium $E\left(\pi_{A}^{n e t}\right)=E\left(\pi_{B}^{n e t}\right)$. Furthermore, realized profits, $\pi_{D}$, expected profits, the realized bonuses, $b_{A}$ and $b_{B}$, and the expected bonuses to the searching skilled workers, $V_{A}$ and $V_{B}$ are uniquely determined by $\lambda_{A}$ and $\lambda_{B}$, which are uniquely defined as the solution to: (i) $\lambda_{B}=$ $\frac{\beta \lambda_{U} \lambda_{A}}{\lambda_{A}-(1-\beta) \lambda_{U}}$ and (ii) $\lambda_{B}=\ln \left(\frac{1-e^{-\lambda_{A}}}{e^{-\lambda_{A} \lambda_{A}}}\right)$. Furthermore, both $\lambda_{A}$ and $\lambda_{B}$ are increasing in $\beta$ and $\lambda_{U}$ and decreasing in $N$.

The proof to proposition 4 is in the appendix. The essence of the proof and the determination of $\lambda_{A}$ and $\lambda_{B}$ can be seen with the help of the following figure 1. In particular, equation (ii) describes a strictly positive and increasing relationship and equation (i) depicts a negatively sloped curve that is greater than zero if and only if $\lambda_{A}>(1-\beta) \lambda_{U}$. Hence, they intersect only once. From these two equations we then have the comparative static results with respect $\beta, \lambda_{U}$, and $\mathrm{N}$ as shown in the figure.

Figure 1: Determination of $\lambda_{A}$ and $\lambda_{B}$

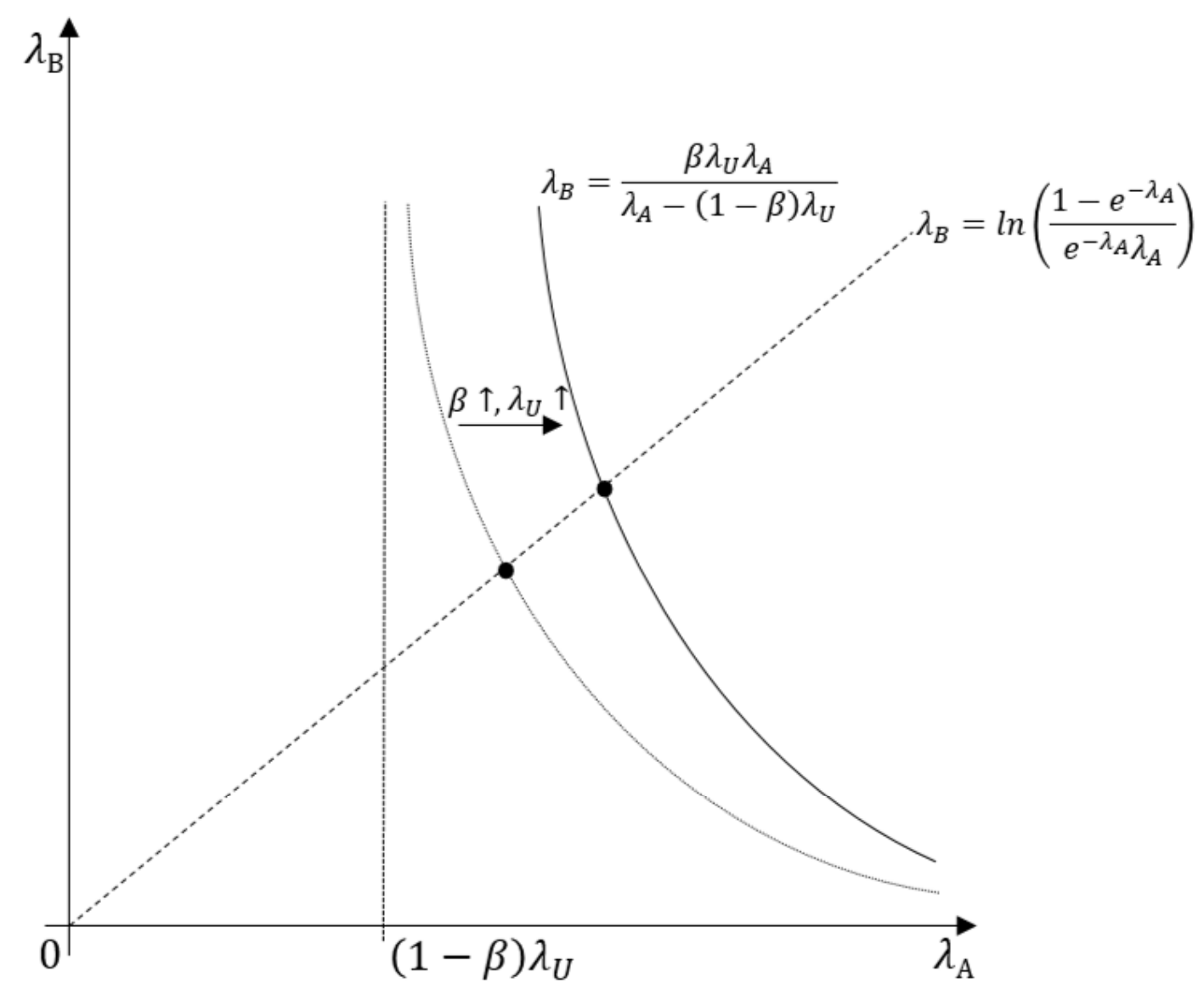


From the results of proposition 4 we can derive the following useful lemma.

Lemma 5. In the unique symmetric SPMCE of the competitive search discriminatory wage posting game $\lambda_{B}<\lambda_{U}<\lambda_{A}$.

Proof. This result follows from $\lambda_{B}=\ln \left(\frac{1-e^{-\lambda_{A}}}{e^{-\lambda_{A} \lambda_{A}}}\right)$, which can be transformed to $\lambda_{B}-\lambda_{A}=\ln \left(\frac{1-e^{-\lambda_{A}}}{\lambda_{A}}\right)=$ $\ln \left(h\left(\lambda_{A}\right)\right)<0$. Thus, $\lambda_{B}=\frac{S_{B}}{N_{B}}<\frac{S_{B}+S_{A}}{N_{B}+N_{A}}=\lambda_{U}<\frac{S_{A}}{N_{A}}=\lambda_{A}$.

This lemma is important because it allows us to compare the discriminatory and non-discriminatory equilibrium.

\subsection{Comparing autarkic equilibria}

When comparing the discriminatory to the non-discriminatory equilibrium, the most important variables are the arrival rate of applicants at the firms and the number of successful matches. Using the result on the arrival rates from lemma 5 we can analyze the number of successful matches by considering the inverse question of the number of unfilled vacancies. We define the average unfilled vacancy rate in the discriminatory equilibrium as:

$$
\Psi(\eta)=\frac{N_{A}}{N} e^{-\lambda_{A}}+\frac{N_{B}}{N} e^{-\lambda_{B}}=\eta e^{-\frac{S_{A}}{\eta N}}+(1-\eta) e^{-\frac{S_{B}}{(1-\eta) N}} .
$$

We now show that $\Psi(\eta)$ is strictly convex in $\eta$, that $\Psi(\eta)$ attains its minimum at $\eta_{\min }=\frac{S_{A}}{S_{A}+S_{B}}$ and that $\Psi\left(\eta_{\min }\right)=e^{-\frac{S_{A}+S_{B}}{N}}=e^{-\lambda_{U}}$. The partial derivative of $\Psi$ with respect to $\eta$ results as: $\frac{\partial \Psi}{\partial \eta}=e^{-\frac{S_{A}}{\eta N}}\left(1+\frac{S_{A}}{\eta N}\right)-e^{-\frac{S_{B}}{(1-\eta) N}}\left(1+\frac{S_{B}}{(1-\eta) N}\right)$. Note that $\frac{\partial \Psi}{\partial \eta}=0$ if $\eta=\frac{S_{A}}{S_{A}+S_{B}}$. To see that $\eta=\frac{S_{A}}{S_{A}+S_{B}}$ is, in fact, a minimizer of $\Psi$, note that $\frac{\partial^{2} \Psi}{\partial \eta^{2}}=e^{-\frac{S A}{\eta N_{D}}} \lambda_{A}^{2} \frac{N_{D}}{N_{A}}+e^{-\frac{S B}{(1-\eta) N_{D}}} \lambda_{B}^{2} \frac{N_{D}}{N_{B}}>0$. Substitution then yields that $\Psi\left(\eta_{\min }\right)=e^{-\frac{S_{A}+S_{B}}{N}}$, which equals the unfilled vacancy rate in the non-discriminatory case since $\frac{S_{A}+S_{B}}{N}=\lambda_{U}$. We state this result as proposition 6 below.

Proposition 6. The number of unfilled vacancies is larger, and the number of successful matches is smaller, in the discriminatory equilibrium.

Proposition 6 is an important result because it will allow us to show that there is less production of the monopolistically competitive good and more of the numeraire good in a discriminatory equilibrium. We then use this result to derive the pattern of comparative advantage. Before we 
consider international trade we compare expected profits, bonuses, and expected income in the discriminatory and non-discriminatory equilibrium.

Using propositions 1 and 3 , and denoting with a subscript $e \in\{U, D\}$ the type of equilibrium we are considering we can rewrite the realized profit of a successful firm as $\pi_{e}=\frac{\alpha}{\sigma-\alpha}\left(\frac{L}{M_{e}}-1\right)-$ $\frac{\sigma f}{\sigma-\alpha}$. After substituting income into the demand for a variety (from equation 7 ) we can write the equilibrium output of a successful firm in either type of equilibrium as $q_{e}=\frac{(\sigma-1) \alpha}{\sigma-\alpha}\left[\frac{L}{M_{e}}-(1+f)\right]$. Now from proposition 6 we know that $M_{D}<M_{U}$, therefore, the realized profits and output of a successful firm are higher in the discriminatory equilibrium: $\pi_{D}>\pi_{U}$ and $q_{D}>q_{U}$. This result is intuitive. If there are less successful firms, then there is less competition and the profits of each producing firm is greater. In comparing expected profits in the discriminatory and nondiscriminatory equilibrium note that $E\left(\pi_{A}^{n e t}\right)=E\left(\pi_{B}^{n e t}\right)$ in equilibrium. Hence, we only need to compare $E\left(\pi_{A}^{n e t}\right)=\left[1-\left(1+\lambda_{A}\right) e^{-\lambda_{A}}\right] \pi_{D}$ in the discriminatory case to $E\left(\pi_{U}^{n e t}\right)=\left[1-\left(1+\lambda_{U}\right) e^{-\lambda_{U}}\right] \pi_{U}$ from the non-discriminatory case. Now, $1-(1+\lambda) e^{-\lambda}$ is increasing in $\lambda$ and from lemma 5 we know that $\lambda_{A}>\lambda_{U}$. Hence, given that $\pi_{D}>\pi_{U}$ we know that the expected profits are also larger in a discriminatory equilibrium. We summarize these results in proposition 7.

Proposition 7. Expected and realized firm profits, and output of each variety, are larger in the discriminatory equilibrium.

The overall effect on workers is not as easy to disentangle. The change in $\lambda$ produces two opposing effects on skilled workers. First, with respect to $A$-label workers, note that holding $\pi$ constant, $b_{A}$ and $V_{A}(\mathbf{b})$ are both decreasing in $\lambda$. Hence, given that $\lambda_{A}>\lambda_{U}$, if $\pi$ does not change, then the bonuses and expected incomes of A-labeled skilled workers are lower in the discriminatory equilibrium. Of course, as shown in proposition 7 the realized profits of each successful firm are higher in the discriminatory equilibrium and part of these profits are passed on to the managers in their bonuses. With respect to the $B$-label managers note that they have a lower bonus and expected bonus than $A$-labels. Their bonus is lower because $b_{B}=V_{A}(\mathbf{b})=h\left(\lambda_{A}\right) b_{A}$ and $h\left(\lambda_{A}\right)<$ 1. In addition, their expected bonus is lower since $V_{B}(\mathbf{b})=h\left(\lambda_{B}\right) b_{B}=h\left(\lambda_{B}\right) V_{A}(\mathbf{b})<V_{A}(\mathbf{b})$.

In figure 2 we see a depiction of the discriminatory and non-discriminatory equilibrium (for the case when the realized firm profits do not rise enough to increase the expected bonus of the skilled workers). The topmost tangency between the firm's iso-profit and the skilled worker's indifference curve indicates the non-discriminatory equilibrium at $\left(\lambda_{U}, b_{U}\right)$. In the discriminatory equilibrium the firm's have higher profits and this is reflected by movement to an iso-profit curve that 
lies to the southeast of the non-discriminatory equilibrium iso-profit curve. In the resulting discriminatory equilibrium the $A$-labels are on a lower indifference curve, with a lower bonus and a lower probability of finding a match (a larger $\lambda$ ). The $B$-labels are on an even lower indifference curve with a much lower bonus, but a greater probability of successfully finding a match. The firm's profits are the same whether or not they post a bonus to attract $A$ - or $B$-label managers. We return to this figure in a later section when we introduce non-discriminatory firms.

Figure 2: The equilibrium with and without discrimination

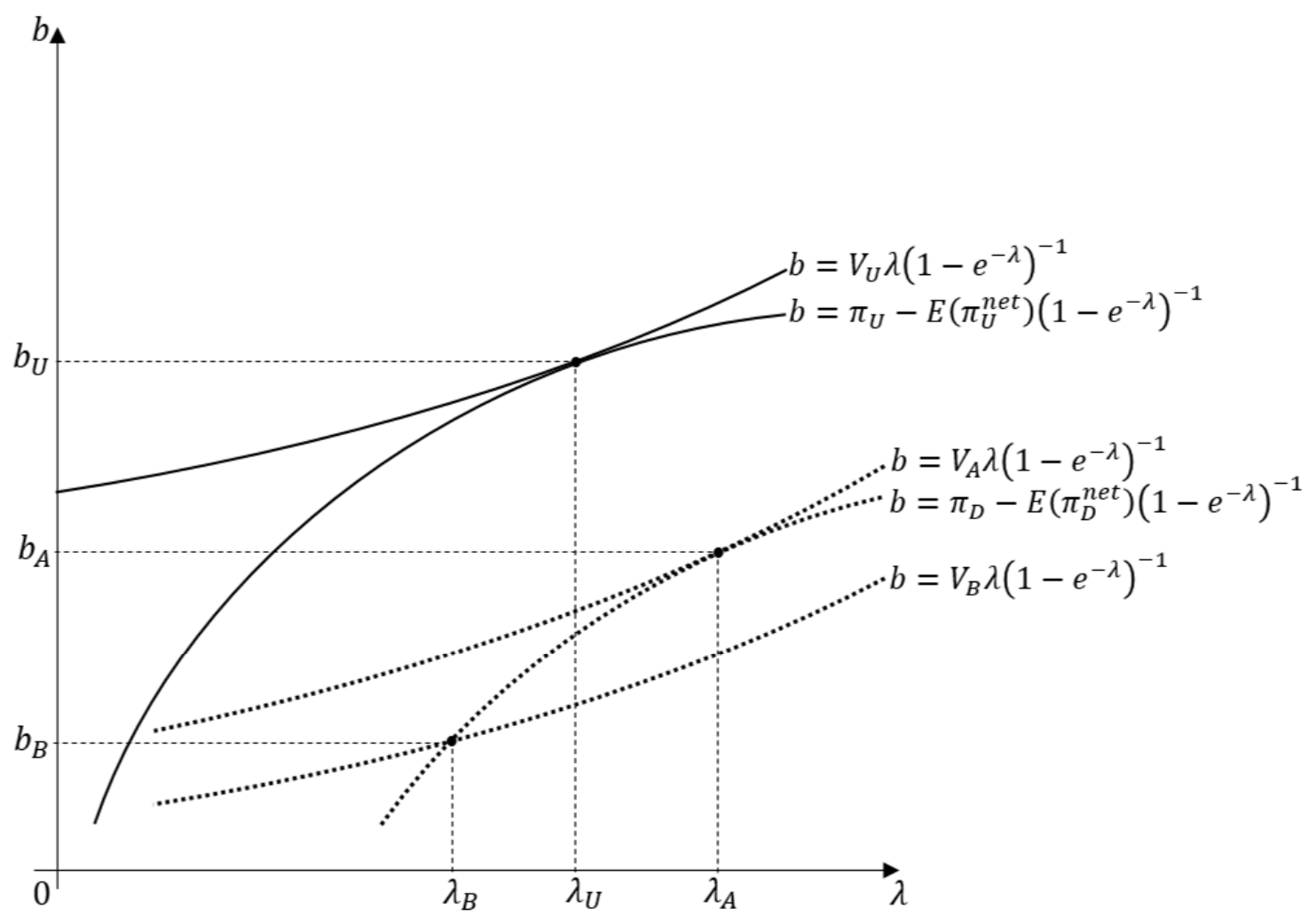

\section{Trade liberalization}

We now consider international trade. In order to analyze the pattern of trade, we begin by deriving the autarkic prices for the home economy, which is in a discriminatory equilibrium, and for the foreign economy, which is initially assumed to be in a label-blind equilibrium. Given that $L=L^{*}$ and $S=S^{*}$, we know from proposition 6 that the number of matches is lower in the home country. 
In particular, $M_{D}<M_{U}=M^{*}$. Hence, production of the monopolistically competitive good is lower in the home country. Given that the vacancy rate is higher, and $L=L^{*}$, the production of the numeraire good must be larger in the home country. From equations (4) through (7) we can then write the relative autarkic prices in Home and Foreign as:

$$
\frac{P_{M}}{P_{0}}=\frac{\alpha}{1-\alpha} \frac{C_{0}}{C_{M}}=M_{D}^{\frac{1}{1-\sigma}} p_{z}>\left(M^{*}\right)^{\frac{1}{1-\sigma}} p_{z}=\frac{P_{M}^{*}}{P_{0}}
$$

We have now established the following result.

Proposition 8. The country in the discriminatory equilibrium has a comparative disadvantage in the manufacturing sector.

We now consider how trade liberalization affects the home and the foreign country. As its manufacturing output falls below the foreign country's manufacturing output, the relative size of the home country's numeraire sector grows from trade liberalization. In addition, the total number of available varieties increases. This produces two counteracting effects: first, the price index $P_{M}$ and a firm's profits are both decreasing in the number of available varieties; second, a firm's profits are increasing in the market size. If the countries were symmetric, these two effects would cancel out: $\pi_{e}^{\text {autarky }}=\frac{\alpha}{\sigma-\alpha}\left(\frac{L}{M_{e}}-1\right)-\frac{\sigma f}{\sigma-\alpha}=\frac{\alpha}{\sigma-\alpha}\left(\frac{2 L}{2 M_{e}}-1\right)-\frac{\sigma f}{\sigma-\alpha}=\pi_{e}^{\text {trade }}$.

When the countries are asymmetric because the home country is in a discriminatory equilibrium we have that for home country firms:

$$
\pi_{D}^{\text {trade }}=\frac{\alpha}{\sigma-\alpha}\left(\frac{2 L}{M_{D}+M^{*}}-1\right)-\frac{\sigma f}{\sigma-\alpha}<\frac{\alpha}{\sigma-\alpha}\left(\frac{L}{M_{D}}-1\right)-\frac{\sigma f}{\sigma-\alpha}=\pi_{D}^{\text {autarky }}
$$

because $M_{D}<M_{U}=M^{*}$. Finally we consider output of each firm. Comparing output in trade and autarky we have:

$$
q_{D}^{\text {trade }}=\frac{(\sigma-1) \alpha}{\sigma-\alpha}\left(\frac{2 L}{M_{D}+M^{*}}-(1+f)\right)<\frac{(\sigma-1) \alpha}{\sigma-\alpha}\left(\frac{L}{M_{D}}-(1+f)\right)=q_{D}^{\text {autarky }}
$$

The output of the monopolistically competitive sector is $M_{D} q_{D}$ and is, therefore, also lower in trade than in autarky. We have now established the following proposition. 
Proposition 9. When liberalizing trade, the output of each manufacturing firm, of the manufacturing sector, and the realized and expected firm profits all fall in the discriminatory country and the output of the numeraire sector increases. The opposite results occur in the label-blind country.

Finally, we use our results for firm profits to note the effect of trade liberalization on skilled workers of both labels. From proposition 3 we see that the change in the skilled workers' realized and expected bonuses resulting from a change in profits can be written as

$$
\frac{\partial b_{B}}{\partial \pi}=h\left(\lambda_{A}\right) \frac{\partial b_{A}}{\partial \pi} ; \quad \frac{\partial V_{B}}{\partial \pi}=h\left(\lambda_{B}\right) \frac{\partial V_{A}}{\partial \pi} .
$$

It is straightforward to see that bonuses and expected incomes of both labels of skilled workers are increasing in realized firm profits and, because $h(\lambda)<1$, that they are increasing faster for $A$-labels. Hence, the decrease in manufacturing firm profits that is driven by the change from autarky to free trade is felt more strongly by the $A$-label than by the $B$-label skilled workers. We summarize this discussion in proposition 10.

Proposition 10. When liberalizing trade the realized and expected bonuses decrease in the discriminatory country and increase in the label-blind country. The change is larger for A-label than for B-label skilled workers.

An interesting implication of proposition 10 is that trade liberalization reduces the remuneration gap (among properly matched skilled workers) in the discriminatory country.

\section{Co-existence of discriminatory and non-discriminatory firms in au- tarky}

We now consider the case in which $N_{0}<\beta N$ non-discriminating firms are also present in the home country. For these firms the label is irrelevant so that when faced with both an $A$-label and a $B$-label managerial applicant each applicant is hired with equal probability. In order to continue to have a clear conception of comparative advantage we assume that the total number of home firms is still $N$ so that $N_{D}=N-N_{0}$ is the number of discriminatory firms. ${ }^{9}$

\footnotetext{
${ }^{9}$ If we allowed for free entry, then we could no longer be certain of $N=N^{*}$ and the total number of matches, as well as the pattern of comparative advantage, would no longer be a simple mapping from the unfilled vacancy rate. In
} 
To develop the intuition for the results that are introduced in this section we refer the reader again to figure 2. In figure 2 we illustrate the equilibrium with only discriminatory firms. We see there that the low bonus offered to the $B$-label applicants generates "too many" firms posting that low bonus in the attempt to attract a $B$-label manager. ${ }^{10}$ Hence, the inefficiency illustrated in figure 2 suggests that a firm that is known not to discriminate could post a bonus (and a corresponding hiring probability) that would attract $B$ and not $A$-label applicants. A discriminatory firm could not post such a bonus (and expect only $B$-label applicants) because it is known that they would show priority to $A$-label applicants. This bonus, $b_{0}$, with corresponding expectation $V_{0}$, and expected profits $E\left(\pi_{0}^{n e t}\right)$, is shown in figure 3 .

particular, it would also depend on the shape of the distribution driving the firm heterogeneity. Although (as will be seen below), a label-blind firm would have larger expected profits than a discriminating one with an equivalent cost, as long as there is some firm heterogeneity (in either fixed or variable costs), then the two types of firms would coexist with free entry. In particular, the cutoff productivity level (fixed cost) would be lower (higher) so that the average cost of the marginal label-blind firm would be higher than that of the marginal discriminatory firm. Even though the pattern of comparative advantage does not admit a simple solution in such an environment we could make predictions on how the number of each type of firm responds to trade liberalization. We save this extension for future research.

${ }^{10} \lambda_{B}<\lambda_{A}$ implies $\frac{\beta S}{N_{B}}<\frac{(1-\beta) S}{N_{A}}$ or $\frac{\beta}{1-\beta}<\frac{N_{B}}{N_{A}}$, therefore, we say "too many" firms post to attract $B$-labels. 
Figure 3: The potential for non-discriminatory firms

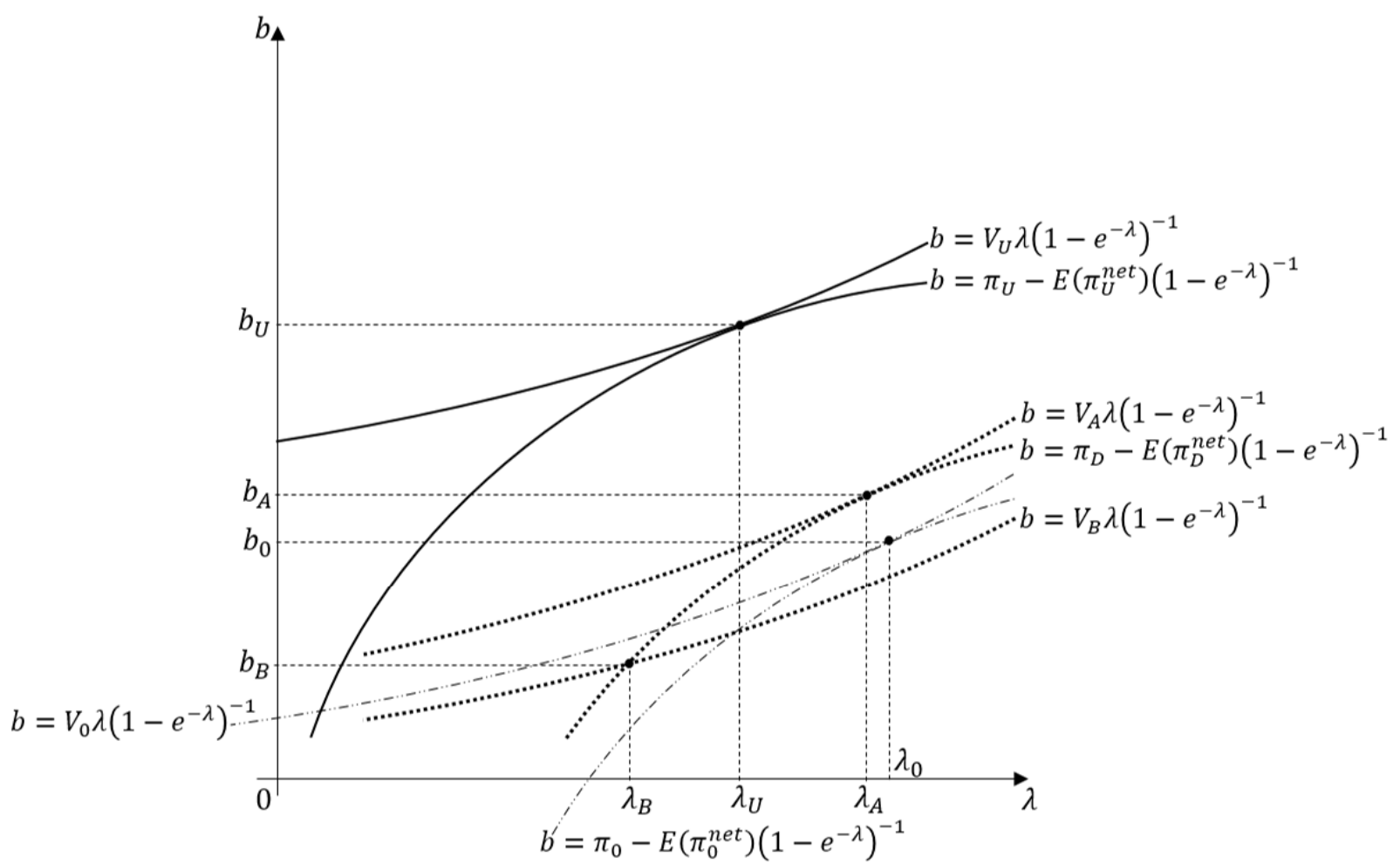

In figure 3 , at $b_{0}$ the $B$-label applicant is on a higher indifference curve and the non-discriminatory firms have larger profits than the discriminatory ones. Of course, figure 3 does not depict the new equilibrium. In equilibrium, a $B$-label must be indifferent between a label-blind and a discriminatory firm, therefore, the bonus offered by the discriminatory firms to the $B$-labels must increase as well. In response to the higher bonus required to attract the $B$-label applicants (and the resulting fewer applicants at the discriminatory $B$-label firms) some discriminatory firms switch from attracting $B$-label applicants to attracting $A$-label applicants.

The new coexistence equilibrium is depicted by the dashed lines in figure 4 (along with the unbiased equilibrium with solid lines and the discriminatory equilibrium with dotted lines). The 
bonuses in the co-existence equilibrium are denoted as $b_{0 B}$ for those offered by the non-discriminatory firms and $b_{D B}$ and $b_{D A}$ for those offered by the discriminatory firms (as the next lemma shows, the non-discriminatory firms do not post a bonus to attract $A$-labels). We see in figure 4 that, compared to the discriminatory equilibrium, the expected profits for discriminatory firms is lower and the expected payment of both labels of applicants is larger in the co-existence equilibrium. Not only is the bonus offered to both labels of applicants larger, but the applicant to position ratio is smaller for both types of discriminatory firms.

Figure 4: The autarky equilibrium with co-existence of discriminating and non-discriminating firms

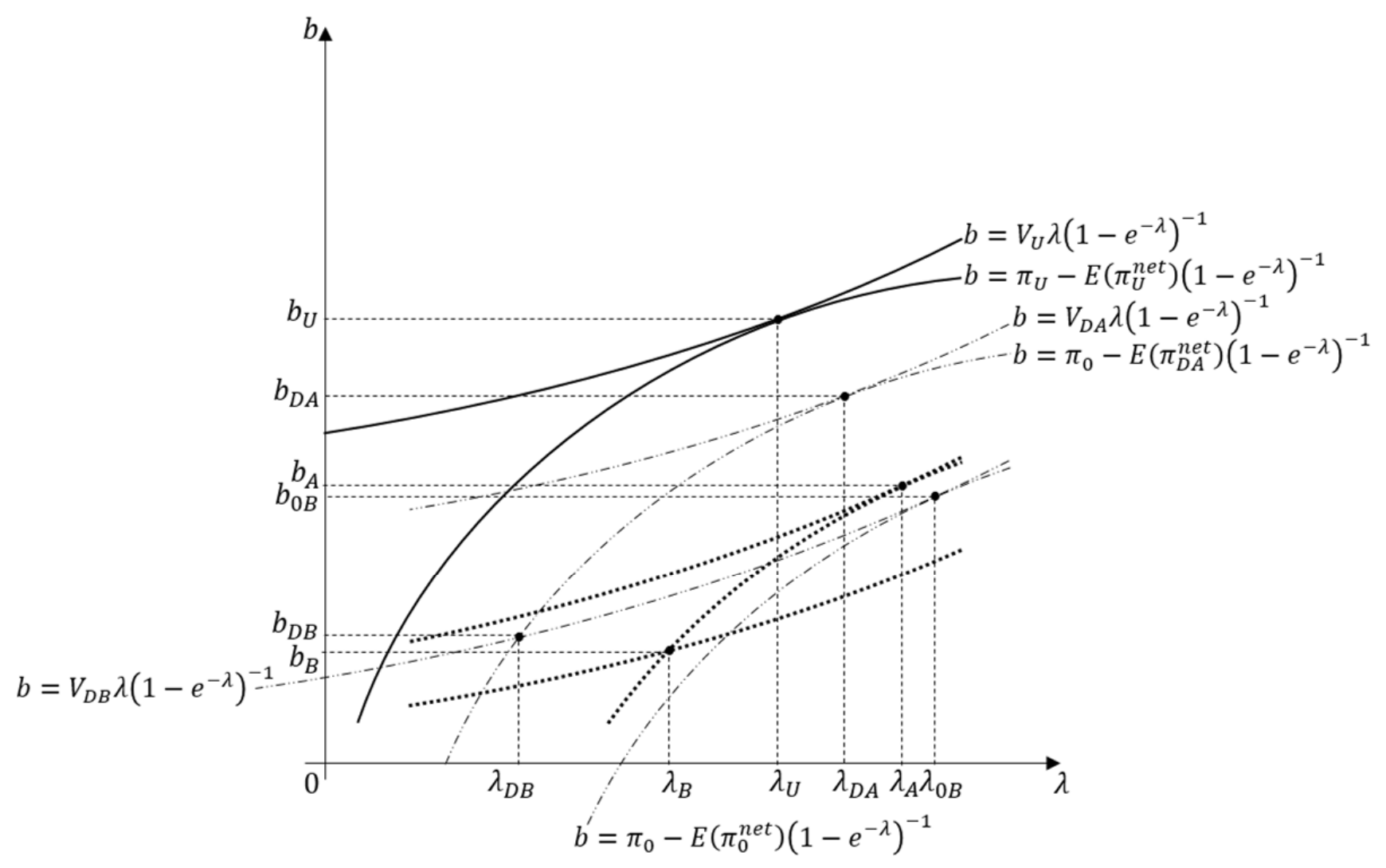


Before proceeding with the formal analysis we introduce the following notation. Of the $N_{D}$ firms $N_{D A}$ will attract only $A$-labels and $N_{D B}$ will attract only $B$-labels in the coexistence equilibrium. Similarly, $N_{0 A}$ and $N_{0 B}$ are the number of label-blind firms attracting only $A$ and only $B$-labels in the coexistence equilibrium. Of the skilled workers, $S_{D A}$ and $S_{D B}$ are the numbers that apply to the discriminatory firms and $S_{0 A}$ and $S_{0 B}$ are the numbers that apply to the non-discriminatory firms. The extension to $\lambda_{D A}, \lambda_{D B}, \lambda_{0 A}$, and to $\lambda_{0 B}$ is straightforward. More generally, we can write $N_{t k}, S_{t k}$, and $\lambda_{t k}$ where $t \in\{D, 0\}$ and $k$ signifies the label of worker attracted by a type $t$ firm. Similarly, $b_{t k}$ is the bonus offered by a type $t$ firm attracting a label- $k$ manager and $V_{t k}$ is the expected bonus.

It will prove useful to consider the skilled workers that apply to the discriminatory firms. The fraction of applicants to discriminatory firms that are $B$-labels is $\beta_{D}=\frac{S_{D B}}{S_{D A}+S_{D B}}$ and the average arrival rate of applicants at discriminatory firms is $\lambda_{D}=\frac{S_{D A}+S_{D B}}{N_{D A}+N_{D B}}$.

We write $M_{0}, \pi_{0}$, and $I_{0}$ for the number of matches, the realized firm profit, and aggregate income in the equilibrium with non-discriminatory firms. We write $E\left(\pi_{0}^{n e t}\right)$ for the expected profits of the non-discriminatory firms and $E\left(\pi_{D A}^{n e t}\right)$ and $E\left(\pi_{D B}^{n e t}\right)$ for that of the discriminatory firms. Of course, in equilibrium the expected profits of all the discriminatory firms are equal.

Note that the restriction $N_{0}<\beta N$ indicates that if the label-blind firms post to attract only $B$-labels and the discriminatory ones post only for all the $A$-labels then we would have $\lambda_{0 B}>\lambda_{U}>\lambda_{D A}$, therefore, it would not replicate the unbiased equilibrium. We now establish the composition of the firms in any equilibrium with $N_{0}<\beta N$ non-discriminatory firms coexisting with $N_{D}=N-N_{0}$ discriminatory ones.

Lemma 11. In any symmetric SPMCE where $N_{0}<\beta N$ non-discriminatory firms coexist with $N_{D}=$ $N-N_{0}$ discriminatory firms all of the label-blind firms post the same bonus, $b_{0 B}>b_{D B}$, and attract only B-label applicants. Hence, $N_{0 B}=N_{0}, N_{0 A}=0$ and, therefore, $S_{D A}=S_{A}$ and $N_{D A}>0$.

The proof to Lemma 11 is in the appendix. It shows that, because the non-discriminatory firms only have an advantage with respect to the $B$-labels, they only attract the $B$-labels in equilibrium. We now show that there is a unique equilibrium with the coexistence of discriminatory and nondiscriminatory firms. In this equilibrium some of the discriminatory firms continue to attract $B$-labels, so that $N_{D B}>0$. In addition, the profit of the label-blind firms is strictly larger than that of the discriminatory firms. 
Proposition 12. There exists a unique symmetric SPMCE with $N_{0}<\beta N$ non-discriminating firms and $N_{D}=N-N_{0}$ discriminating firms. In this equilibrium $0=\lambda_{0 A}, 0<\lambda_{D B}<\lambda_{B}, 0<\lambda_{D A}<\lambda_{A}$, $\lambda_{D B}<\lambda_{0 B}$, and $E\left(\pi_{0}^{n e t}\right)>E\left(\pi_{D A}^{n e t}\right)=E\left(\pi_{D B}^{n e t}\right)$.

The proof to proposition 12 is in the appendix. It is related to the proof of proposition 4 , but now there are three types of firms.

An additional facet of the equilibrium with $N_{0}$ non-discriminatory firms is that, holding realized profits constant, we have $V_{0 B}=V_{D B}>V_{B}$ and $V_{D A}>V_{A}$ as seen in figure 4 . To see the first point consider equation (23) from the appendix and note that $\lambda_{D B}<\lambda_{B}$ and that $\lambda_{D A}<\lambda_{A}$. To see the second point note that $V_{D A}=\pi e^{-\lambda_{D A}}$ which is decreasing in $\lambda_{D A}$. In addition, using appendix equation (24) and the left hand side of (23) yields that $V_{0 B}=\pi_{0} e^{-\lambda_{0 B}}$ which, combined with the fact that $V_{0 B}=V_{D B}<V_{D A}$, yields that $\lambda_{0 B}>\lambda_{D A}>\lambda_{D B}$ as seen in figure 4. Similarly, holding realized profits constant and noting that $E\left(\pi_{D A}^{n e t}\right)=E\left(\pi_{D B}^{n e t}\right)$, that $E\left(\pi_{D A}^{n e t}\right)$ is increasing in $\lambda$, and that $\lambda_{D A}<\lambda_{A}$ we see that expected firm profits of the discriminatory firms are lower in the coexistence equilibrium than in the fully discriminatory equilibrium without any label-blind firms.

In order to analyze the full effect of the non-discriminatory firms on expected bonuses and expected profits we also need to consider how realized firm profits are affected. As in the previous cases, realized firm profits in the coexistence equilibrium, $\pi_{0}$, are a function of the number of successful matches, $M_{0}=M_{0 B}+M_{D B}+M_{D A}$, as well as several exogenous variables that do not depend on the particular equilibrium under consideration. We, therefore, now consider the unfilled vacancy rate in the equilibrium with $N_{D}$ discriminatory and $N_{0}$ label-blind firms. The average unfilled vacancy rate in this equilibrium can be written as:

$$
\Psi_{0}=\frac{N_{D A}}{N} e^{-\lambda_{D A}}+\frac{N_{D B}}{N} e^{-\lambda_{D B}}+\frac{N_{0 B}}{N} e^{-\lambda_{0 B}}=\eta_{A} e^{-\frac{S_{A}}{\eta_{A} N}}+\left(1-\eta_{A}-\eta_{0}\right) e^{-\frac{s_{D B}}{\left(1-\eta_{A}-\eta_{0}\right) N}}+\eta_{0} e^{-\frac{S_{0 B}}{\eta_{0} N}},
$$

where $\eta_{A}=\frac{N_{D A}}{N}$ and $\eta_{0}=\frac{N_{0}}{N}$. The partial derivative of this vacancy rate with respect to the portion of non-discriminatory firms is:

$$
\frac{\partial \Psi_{0}}{\partial \eta_{0}}=\left(1+\lambda_{0 B}\right) e^{-\lambda_{0 B}}-\left(1+\lambda_{D B}\right) e^{-\lambda_{D B}}<0 .
$$


To see that equation (18) is strictly negative note that $(1+\lambda) e^{-\lambda}$ is strictly decreasing in $\lambda$ and remember from proposition 12 that $\lambda_{0 B}>\lambda_{D B}$. Hence, an increase in the portion of non-discriminatory firms yields a greater number of matches which in turn reduces the realized firm profits of successful firms. This reduced profit reinforces the negative effect on discriminatory firm profits discussed in the previous paragraph but renders ambiguous the effect on the skilled workers' expected bonus.

We state the results of the previous two paragraphs as proposition 13.

Proposition 13. In the unique symmetric SPMCE with $N_{0}<\beta N$ non-discriminating firms and $N_{D}=$ $N-N_{0}$ discriminating firms the expected number of successful matches is increasing in the number of labelblind firms. Expected firm profits of the discriminatory firms are lower in the coexistence equilibrium and they are decreasing in $N_{0}$.

An important implication of proposition 13 is that, if there are two economies that differ only in the portion of label-blind firms (while holding the total number of firms constant), then the country with more discriminatory firms would have a comparative advantage in the numeraire sector. We analyze this implication in the following section.

\section{Can trade ameliorate discrimination?}

We start by analyzing the pattern of trade in our augmented model where label-blind firms coexist with discriminatory ones. Remembering that $p_{z}=\frac{\sigma}{\sigma-1}$, we can rewrite equation (13) as:

$$
\frac{P_{M}}{P_{0}}=\frac{\alpha}{1-\alpha} \frac{C_{0}}{C_{M}}=\frac{\left(M_{0}\right)^{\frac{1}{1-\sigma}} \sigma}{\sigma-1}>\frac{\left(M_{0}^{*}\right)^{\frac{1}{1-\sigma}} \sigma}{\sigma-1}=\frac{P_{M}^{*}}{P_{0}} .
$$

Analysis of equation (19) reveals that the only determinant of comparative advantage is the expected number of matches. Hence, if the home and foreign countries only differ in the proportion

of label-blind firms, we can then say that the more discriminatory country is the one that has a smaller number of label-blind firms. A natural corollary of propositions 8 and 13 is then that comparative advantage can be determined solely from the relative proportions of label-blind firms in each country. 
Proposition 14. If the home country has $N_{D}$ discriminatory and $N_{0}<\beta N$ non-discriminatory firms, the foreign country has $N_{D}^{*}$ discriminatory and $N_{0}^{*}<\beta N^{*}$ label-blind firms, the total number of firms is the same, $N=N^{*}$, and technology is the same in both countries, then the country with more discriminatory firms has a comparative advantage in the numeraire sector.

Proof. Immediate from propositions 8 and 13.

From proposition 14 we can then say that a greater degree of discrimination can cause a country to become an exporter of simpler products and a net importer of products from the more sophisticated manufacturing sector.

The introduction of some non-discriminatory firms also allows us to consider the effect of trade liberalization on the prevalence of discrimination. In particular, we analyze how the movement from autarky to free trade affects the expected profits of discriminatory and non-discriminatory firms. The important difference between the two types of firms is that the label-blind firms have larger expected profits. The realized profits of all successful firms in the coexistence equilibrium with trade, $\pi_{0}^{\text {trade }}$, is the same, however, a label-blind firm receives a greater proportion of that profit in expectation. Hence, the effect of trade liberalization on realized profits has a larger, magnified, effect on the expected profits of non-discriminatory firms.

Proposition 15. In the movement from autarky to free trade the expected profits of the label-blind firms will change by more than than those of the discriminatory firms. Hence, trade liberalization will disproportionately affect the non-discriminatory firms.

Proof. From proposition 12 we have that $E\left(\pi_{0}^{n e t}\right)>E\left(\pi_{D A}^{n e t}\right)=E\left(\pi_{D B}^{n e t}\right)$. For all successful firms the realized profits are the same, therefore, the non-discriminatory firms receive a larger expected portion of the realized profits and any change in the realized profits generates a larger change in the expected profits of the non-discriminatory firms.

Proposition 15 suggests that trade liberalization will make it more costly to discriminate in countries where there are fewer discriminatory firms and less costly where it is already more prevalent. In this way trade liberalization will magnify the good and the bad institutions that a country has in autarky.

Propositions 12 and 15 together provide some support and some limitations of the suggestion in Becker (1957) and Arrow (1972) that the market can ameliorate discrimination. First, proposition 
12 shows that non-discriminatory firms earn larger expected profits (the extra cost that discriminatory firms pay for their preferences are in the form of a reduced matching rate), which provides some support for Becker's hypothesis. On the other hand, proposition 15 shows that trade liberalization can reinforce a country's market imperfections (and perfections) and affect the expected profits of label-blind firms by more than those of discriminatory firms.

\section{Conclusion}

We embed a competitive search model with labor market discrimination into a two-sector, twocountry framework in order to analyze the relationship between international trade and labor market discrimination. Discrimination reduces the matching probability and output in the skilledlabor intensive differentiated-product sector so that the country with more discriminatory firms has a comparative advantage in the simple sector. As countries alter their production mix in accordance with their comparative advantage, trade liberalization can then reinforce the negative effect of discrimination on development in the more discriminatory country and reduce its effect in the country with fewer discriminatory firms. Similarly, as a result of globalization, the profit difference between non-discriminatory and discriminatory firms increases in the less discriminatory country and diminishes in the more discriminatory one. In this way trade can further reduce discrimination in a country where it is less prevalent and increase it where it is more firmly entrenched.

\section{Appendix: proofs.}

Proposition 1. There exists a unique symmetric SPMCE in which all firms offer an identical bonus $b_{U}=$ $\frac{\pi_{U} \lambda_{U}}{e^{\lambda_{U}-1}}$ and all skilled workers adopt the same mixed application strategy in which they apply at each single firm with the same probability. A single skilled worker's expected bonus is given by $V_{U}=\pi_{U} e^{-\lambda_{U}}$, profits of each operating firm result as $\pi_{U}=\frac{1}{\sigma-\alpha}\left(\alpha\left[\frac{L}{N\left(1-e^{-\lambda} U\right)}-1\right]-\sigma f\right)$ and expected profits of each firm net of bonus payments are given by $E\left(\pi_{U}^{n e t}\right)=\left[1-\left(1+\lambda_{U}\right) e^{-\lambda_{U}}\right] \pi_{U}$. National income results as $I_{U}=$ $\frac{\sigma}{\sigma-\alpha}\left[L-(1+f) M_{U}\right]$ and the number of operating firms is given by $M_{U}=S \frac{1-e^{-\lambda_{U}}}{\lambda_{U}}=N\left(1-e^{-\lambda_{U}}\right)$.

Proof. Since a skilled worker will only apply with positive probability at the firm(s) which offer(s) the highest bonus, the equilibrium expected bonus for a skilled worker is $V_{U}=\max _{z}\left\{V_{z}\right\}$, where 
Hence, in equilibrium, a firm will only receive applicants if it offers the highest bonus: $\lambda_{z}>0$ and $V_{z}=V_{U}$ for $b_{z} \geq V_{U} ; \lambda_{z}=0$ and $V_{z}=b_{z}$ for $b_{z}<V_{U}$.

Thus, for $b_{z} \geq V_{U}$ we have $\lambda_{z}=h^{-1}\left(\frac{V_{U}}{b_{z}}\right)$. Then, for any firm choosing $b_{z} \geq V_{U}$ the expected number of applicants is $\lambda_{z}$. In equilibrium the expected number of applicants to all firms is:

$$
\sum_{z=1}^{N} \lambda_{z}=\sum_{z \mid b_{z} \geq V_{U}} h^{-1}\left(\frac{V_{U}}{b_{z}}\right)=S .
$$

Note that $h$ is strictly decreasing in $\lambda_{z}$. Therefore, $h^{-1}$ is strictly decreasing in $V_{U}$ and the number of terms in the summand is weakly decreasing in $V_{U}$. Hence, for a given vector of bonus offers $\mathbf{b}$ there exists a unique solution $V_{U}$ to the above equation. Given $V_{U}$ and the vector of bonus offers $\mathbf{b}$, each $\lambda_{z}$ follows from $\lambda_{z}=h^{-1}\left(\frac{V_{U}}{b_{z}}\right)$. Notice that, from the perspective of a single firm, $V_{U}$ is constant and independent of the firm's own bonus offer due to the large number of firms and skilled workers.

Given this relationship between $\lambda z$ and $b_{z}$, we can now solve for the equilibrium of the entire wage-posting game by determining the firms' optimum bonus offers. From $V_{z}=b_{z} h(\lambda)$ we get $b_{z}=\frac{V_{z}}{h\left(\lambda_{z}\right)}$. Considering that $h\left(\lambda_{z}\right)=\frac{1-e^{-\lambda_{z}}}{\lambda_{z}}$, we can thus rewrite the expected profits net of payment to a manager as follows: $E\left(\pi_{z}^{n e t}\right)=\left(1-e^{-\lambda_{z}}\right) \pi_{z}-\lambda_{z} V$. The value of $\lambda_{z}$ which maximizes $E\left(\pi_{z}^{n e t}\right)$ results as $\lambda_{z}=\ln \left(\frac{\pi_{z}}{V(\mathbf{b})}\right)$. This latter expression can be transformed to $V(\mathbf{b})=\frac{\pi}{e^{\lambda}}$. Considering that $V(\mathbf{b})=b h(\lambda)$, we can derive the bonus which maximizes $E\left(\pi_{z}^{n e t}\right)$ by equating $\frac{\pi}{e^{\lambda}}$ with $b h(\lambda)$ and solving for $b: b=\frac{\pi \lambda}{e^{\lambda}-1}$. As a consequence, we can rewrite the expected equilibrium profits of a firm $z$, net of payments to a manager, as $E\left(\pi_{z}^{n e t}\right)=\left[1-(1+\lambda) e^{-\lambda}\right] \pi$. Since all firms offer an identical bonus in equilibrium, potential managers apply at all firms with an identical probability, therefore, $\lambda_{U}=\frac{S}{N}$. Thus, we can also solve for $M_{U}: M_{U}=S \frac{1-e^{-\lambda_{U}}}{\lambda_{U}}=N\left(1-e^{-\lambda_{U}}\right)$.

The profit maximizing pricing rule for each single firm $z$ is given by $p=\frac{\sigma}{\sigma-1}$. The consumers' utility maximizing consumption choices are given by the demands functions in equations (5)-(7).

In solving for market clearing, note that since all manufacturing firms charge an identical price in equilibrium, they all sell the same amount of their variety. Thus, demand for the numeraire good relative to demand for a single variety of the manufacturing good is given by: $\frac{C_{0}}{c}=M \frac{\sigma}{\sigma-1} \frac{1-\alpha}{\alpha}$. Labor market clearing implies that $L-S h(\lambda)=L-M$ workers work as unskilled workers, and $M(q+f)=L_{M}$ of these unskilled workers work in the monopolistically competitive sector. Hence, $C_{0}=L-S h(\lambda)-L_{M}=L-M(1+q+f)$. The total number of skilled workers is $S$, therefore, 
the number of skilled workers who work as unskilled is $S-M=S[1-h(\lambda)]$. The condition that relative supply equals relative demand therefore becomes: $\frac{L-M(1+q+f)}{q}=M \frac{\sigma}{\sigma-1} \frac{1-\alpha}{\alpha}$. Thus, $q_{U}=\alpha \frac{\sigma-1}{\sigma-\alpha}\left[\frac{L}{M_{U}}-(1+f)\right]$.

National income is given as the sum of the wage bill plus expected profits plus the expected payment to the managers. The $L-S$ unskilled workers each receive a wage of one. The $S$ skilled workers have an expected return of $V+\left(1-\frac{M}{S}\right)$, where $\frac{M}{S}$ is the probability of a successful match. The profits of the $M$ successful firms, $\pi-b$, are shared equally by all agents and in equilibrium $V=$ $\frac{M b}{S}$. Hence, total income is $I=L-S+\left[V+\left(1-\frac{M}{S}\right)\right] S+M(\pi-b)=L+M(\pi-1)$. Substituting from equation (8) for firm profits yields $I_{U}=\frac{\sigma}{\sigma-\alpha}\left[L-(1+f) M_{U}\right]$.

Since $\pi=\frac{q}{\sigma-1}-f$, profits of an operating firm result as: $\pi=\frac{\alpha}{\sigma-\alpha}\left[\frac{L}{M_{U}}-(1+f)\right]-f$. We can then use this expression for $\pi_{U}$ and $\lambda_{U}=\frac{S}{N}$ to solve for $E\left(\pi_{U}^{n e t}\right), b_{U}$, and $V_{U}$. Then we can solve for the aggregate price index $P_{M}$ and consumption of the two aggregate goods $C_{0}$ and $C_{M}$.

Finally note that $V_{U}=\frac{e^{-\lambda_{U}}}{\sigma-\alpha}\left(\alpha\left[\frac{L}{N\left(1-e^{-\lambda_{U}}\right)}-1\right]-\sigma f\right)$ which is increasing in $L$ and decreasing in S. Hence, if $L$ is sufficiently large compared to $S$, then $V_{U}>1$ and since $V_{U}>1$, all skilled workers search for a managerial job.

Lemma 2. In any symmetric SPMCE firms separate so that a firm chooses a bonus that will attract only A-label applicants or only B-label applicants, but not both.

Proof. The probability that a firm receives no $A$-label applicants is $\operatorname{Pr}\left(\lambda_{A}=0\right)=\left(1-a_{A}\right)^{S_{A}} \rightarrow$ $e^{-a_{A} S_{A}}=e^{-\lambda_{A}}$. For $B$-label skilled workers, they would be hired with equal probability if and only if no $A$-labels apply. Hence, the probability that an additional $B$-applicant is hired is: $h\left(\lambda_{A}, \lambda_{B}\right)=$ $e^{-\lambda_{A}} h\left(\lambda_{B}\right)=e^{-\lambda_{A}} \frac{1-e^{-\lambda_{B}}}{\lambda_{B}}$.

The expected bonus for a $B$-label applying to a firm $z$ is: $V_{B z}=h\left(\lambda_{A z}, \lambda_{B z}\right) b_{B z}$. The expected equilibrium bonus is $V_{B}=\max _{z}\left\{h\left(\lambda_{A z}, \lambda_{B z}\right) b_{B z}\right\}$.

As in the case for $A$-label skilled workers, no $B$-label will apply to a firm which offers $b_{B z} \leq V_{B}(\mathbf{b})$. Furthermore, there exists a $\bar{b}$ (b)such that for all $b>\bar{b}$ (b) too many A-labels would apply and, therefore, no $B$-label would expect to be hired and no $B$-label worker would apply. Hence, $\lambda_{B z}=0$ for $b_{z} \leq V_{B}(\mathbf{b}), \lambda_{B z}=0$ for $b_{z} \geq \bar{b}(\mathbf{b})$ and $\lambda_{B z}>0$ only for $V_{B}(\mathbf{b})<b_{z}<\bar{b}(\mathbf{b})$.

We now consider the firms' optimal bonus choice. If a firm $z$ attracts both $A$-label and $B$-label 
applicants, the firm's expected net profit is:

$$
E\left(\pi_{z}^{n e t}\right)=E\left(\pi_{A}^{n e t}\right)+E\left(\pi_{B}^{n e t}\right)=\left(1-e^{-\lambda_{A}}\right)\left(\pi_{z}-b_{z}\right)+e^{-\lambda_{A}}\left(1-e^{-\lambda_{B}}\right)\left(\pi_{z}-b_{z}\right)
$$

The firm's optimal choice of bonus satisfies $\frac{\partial E\left(\pi_{z}^{\text {net }}\right)}{\partial b_{z}}=0$, or

$$
e^{-\lambda_{A}} e^{-\lambda_{B}}-1+e^{-\lambda_{B}} e^{-\lambda_{B}}\left(\pi_{z}-b_{z}\right)\left(\frac{\partial \lambda_{A}}{\partial b_{z}}+\frac{\partial \lambda_{B}}{\partial b_{z}}\right)=0,
$$

however, if $\frac{\partial \lambda_{A}}{\partial b_{z}}+\frac{\partial \lambda_{B}}{\partial b_{z}}<0$, then $\frac{\partial E\left(\pi_{z}^{n e t}\right)}{\partial b_{z}}<0$. In this case a firm choosing a bonus that is large enough to attract $A$ - and $B$-label workers would want to lower the offered bonus and then only attract $B$-label workers. Notice that the condition $\frac{\partial \lambda_{A}}{\partial b_{z}}+\frac{\partial \lambda_{B}}{\partial b_{z}}<0$ says that an increase in the offered bonus would decrease the number of $B$-label applicants by more than it would increase the number of $A$-label applicants. Hence, a reduction in the bonus would increase the number of $B$-level applicants by more than it would decrease the number of $A$-label applicants and no firm would ever choose a bonus that attracts both labels of potential managers.

Rewriting the term for the expected market bonus leads to: $V_{B}(\mathbf{b})=b_{z} e^{-\lambda_{A}} h\left(\lambda_{B}\right)$ and $V_{A}(\mathbf{b})=$ $b_{z} h\left(\lambda_{A}\right)$, where $h\left(\lambda_{k}\right)=\frac{1-e^{-\lambda_{k}}}{\lambda_{k}}$. We now show that totally differentiating these two equations with respect to the (common) bonus and holding the aggregates constant yields that $\frac{\partial \lambda_{A}}{\partial b_{z}}+\frac{\partial \lambda_{B}}{\partial b_{z}}<0$. Totally differentiating $V_{B}=b_{z} e^{-\lambda_{A}} \frac{1-e^{-\lambda_{B}}}{\lambda_{B}}$ and $V_{A}=b_{z} \frac{1-e^{-\lambda_{A}}}{\lambda_{A}}$, considering that $V_{B}$ and $V_{A}$ are constant from a single firm's perspective and solving for $\frac{d \lambda_{B}}{d b}$ and $\frac{d \lambda_{A}}{d b}$ leads to:

$$
\begin{gathered}
\frac{d \lambda_{A}}{d b}=-\frac{\left(1-e^{-\lambda_{A}}\right) \lambda_{A}}{b\left(e^{\left.-\lambda_{A} \lambda_{A}-1+e^{-\lambda_{A}}\right)}\right.} \\
\frac{d \lambda_{B}}{d b}=-\frac{\lambda_{B}\left(1-e^{-\lambda_{B}}\right)\left(\lambda_{A}-1+e^{-\lambda_{A}}\right)}{\left(e^{-\lambda_{B}} \lambda_{B}-1+e^{-\lambda_{B}}\right) b\left(e^{-\lambda_{A} \lambda_{A}}-1+e^{-\lambda_{A}}\right)} .
\end{gathered}
$$

Thus, we get:

$$
\begin{gathered}
\frac{d \lambda_{A}}{d b}+\frac{d \lambda_{B}}{d b}=-\frac{1}{b} \frac{\lambda_{A}\left(e^{\lambda_{A}}-1\right)}{\left(e^{\lambda_{A}}-\lambda_{A}-1\right)}\left[\frac{\lambda_{B}\left(e^{\lambda_{B}}-1\right)}{2\left(e^{\lambda_{B}}-\lambda_{B}-1\right)} \frac{2\left(\lambda_{A} e^{\lambda_{A}}-e^{\lambda_{A}}+1\right)}{\lambda_{A}\left(e^{\lambda_{A}}-1\right)}-1\right] . \\
\frac{d \lambda_{A}}{d b}+\frac{d \lambda_{B}}{d b}<0 \text { since } e^{\lambda_{A}}-\lambda_{A}-1>0, \frac{\lambda_{B}\left(e^{\lambda_{B}}-1\right)}{2\left(e^{\left.\lambda_{B}-\lambda_{B}-1\right)}\right.}>1 \text { and } \frac{2\left(\lambda_{A} e^{\left.\lambda_{A}-e^{\lambda_{A}+1}\right)}\right.}{\lambda_{A}\left(e^{\lambda_{A}-1}\right)}>1 .
\end{gathered}
$$

Proposition 3. In any symmetric SPMCE with discrimination we have: (i) $b_{A}=\frac{\pi_{A} \lambda_{A}}{e^{\lambda_{A}-1}}, V_{A}(\mathbf{b})=\pi_{D} e^{-\lambda_{A}}$ 
and $E\left(\pi_{A}^{n e t}\right)=\left[1-\left(1+\lambda_{A}\right) e^{-\lambda_{A}}\right] \pi_{D}$; (ii) $\pi_{D}=\frac{1}{\sigma-\alpha}\left(\alpha\left[\frac{L}{M_{D}}-1\right]-\sigma f\right)$, where $M_{D}=S_{B} \frac{1-e^{-\lambda_{B}}}{\lambda_{B}}+$ $S_{A} \frac{1-e^{-\lambda_{A}}}{\lambda_{A}}$; (iii) $b_{B}=V_{A}(\mathbf{b}), V_{B}(\mathbf{b})=\pi_{D} e^{-\lambda_{A}} \frac{1-e^{-\lambda_{B}}}{\lambda_{B}}$ and $E\left(\pi_{B}^{n e t}\right)=\left(1-e^{-\lambda_{B}}\right)\left(1-e^{-\lambda_{A}}\right) \pi_{D}$; (iv) $I_{D}=\frac{\sigma}{\sigma-\alpha}\left[L-(1+f) M_{D}\right]$.

Proof. The derivations for parts (i) and (ii) are identical to the derivations in the case without discrimination and are shown in proposition 1. For part (iii) note that for the firms that attract $B$-label applicants we must have $b_{B} \leq V_{A}$ (b) because $A$-label workers will apply if $b_{B}>V_{A}(\mathbf{b})$. If $b_{B} \leq V_{A}$ (b) then only $B$-labels will apply. Hence, $b_{B}=V_{A}(\mathbf{b})$. Then, $V_{B}(\mathbf{b})=V_{A}(\mathbf{b}) h\left(\lambda_{B}\right)=$ $V_{A}(\mathbf{b}) \frac{1-e^{-\lambda_{B}}}{\lambda_{B}}=\frac{1-e^{-\lambda_{B}}}{\lambda_{B}} \pi_{D} e^{-\lambda_{A}}$ and $E\left(\pi_{B}^{n e t}\right)=\left(1-e^{-\lambda_{B}}\right)\left[\pi_{D}-V_{A}(\mathbf{b})\right]=\left(1-e^{-\lambda_{B}}\right)\left(1-e^{-\lambda_{A}}\right) \pi_{D}$.

Similar to the non-discriminatory case we can write total income as $I=L-S+\left[V_{A}+\left(1-\frac{M_{A}}{S_{A}}\right)\right] S_{A}+\left[V_{B}+\left(1-\frac{M_{B}}{S_{B}}\right)\right] S_{B}+M_{A}\left(\pi_{D}-b_{A}\right)+M_{B}\left(\pi_{D}-b_{B}\right)=L+M_{D}\left(\pi_{D}-1\right)$. Substituting from equation (8) for firm profits yields $I_{D}=\frac{\sigma}{\sigma-\alpha}\left[L-(1+f) M_{D}\right]$.

The output of a single operating firm in the monopolistically competitive sector is then given as $q_{D}=\alpha \frac{\sigma-1}{\sigma-\alpha}\left[\frac{L}{M_{D}}-(1+f)\right]$ and the profits of an operating firm is $\pi_{D}=\frac{1}{\sigma-\alpha}\left(\alpha\left[\frac{L}{M_{D}}-1\right]-\sigma f\right)$.

We can then use this expression for $\pi_{D}$ and $\lambda_{k}=\frac{S_{k}}{N_{k}}$ to solve for $b_{k}$ and $V_{k}$ for $k \in\{a, B\}$. Then we can solve for the aggregate price index $P_{M}$ and consumption of the two (aggregate) goods $C_{0}$ and $C_{M}$.

Finally, note that $V_{B}=\frac{1-e^{-\lambda_{B}}}{\lambda_{B}} \frac{e^{-\lambda_{A}}}{\sigma-\alpha}\left(\alpha\left[\frac{L}{N_{A}\left(1-e^{-\lambda_{A}}\right)+N_{B}\left(1-e^{-\lambda_{B}}\right)}-1\right]-\sigma f\right)$ which is increasing in $L$ and decreasing in $S_{A}$ and in $S_{B}$. Hence, if $L$ is sufficiently large compared to $S$, then $V_{B}>1$ and, because $V_{A}>V_{B}$, we know that $V_{A}>1$ so that all skilled workers will apply for a managerial position.

Proposition 4. There is a unique symmetric SPMCE of this competitive search wage posting game with discrimination. In this equilibrium $E\left(\pi_{A}^{n e t}\right)=E\left(\pi_{B}^{\text {net }}\right)$. Furthermore, realized profits, $\pi_{D}$, expected profits, the realized bonuses, $b_{A}$ and $b_{B}$, and the expected bonuses to the searching skilled workers, $V_{A}$ and $V_{B}$ are uniquely determined by $\lambda_{A}$ and $\lambda_{B}$ which are uniquely defined as the solution to: (i) $\lambda_{B}=$ $\frac{\beta \lambda_{U} \lambda_{A}}{\lambda_{A}-(1-\beta) \lambda_{U}}$ and (ii) $\lambda_{B}=\ln \left(\frac{1-e^{-\lambda_{A}}}{e^{-\lambda_{A} \lambda_{A}}}\right)$. Furthermore, both $\lambda_{A}$ and $\lambda_{B}$ are increasing in $\beta$ and $\lambda_{U}$ and decreasing in $N$.

Proof. First note that $E\left(\pi_{A}^{n e t}\right)$ is increasing in $\lambda_{A}$ and, therefore, is decreasing in $N_{A}$. Second note that $E\left(\pi_{B}^{n e t}\right)$ is increasing in $\lambda_{B}$ and decreasing in $\lambda_{A}$ and, therefore, is decreasing in $N_{B}$ and 
increasing in $N_{A}$. Hence, in equilibrium the number of firms attracting $A$ - and $B$-label applicants will adjust until $E\left(\pi_{A}^{n e t}\right)=E\left(\pi_{B}^{n e t}\right)$. Second note that using $\beta=\frac{S_{B}}{S_{B}+S_{A}}$ and $\lambda_{U}=\frac{S_{A}+S_{B}}{N}$, we can write: $\lambda_{B}=\frac{S_{B}}{N_{B}}=\beta \frac{\lambda_{U} N}{N_{B}}=\beta \frac{\lambda_{U} N}{N_{B}} \frac{\lambda_{A}}{\lambda_{A}}=\frac{\beta \lambda_{U} \lambda_{A}}{\frac{\lambda_{A} N_{B}}{N}}$, which we can further transform to: $\lambda_{B}=$ $\frac{\beta \lambda_{U} \lambda_{A}}{\frac{\lambda_{A}\left(N-N_{A}\right)}{N}}=\frac{\beta \lambda_{U} \lambda_{A}}{\lambda_{A}-\frac{\lambda_{A} N_{A}}{N}}=\frac{\beta \lambda_{U} \lambda_{A}}{\lambda_{A}-\frac{\Lambda_{A}}{N}}=\frac{\beta \lambda_{U} \lambda_{A}}{\lambda_{A}-(1-\beta) \lambda_{U}}$. Third, note that from $E\left(\pi_{A}^{n e t}\right)=E\left(\pi_{B}^{n e t}\right)$ it follows that $1-\left(1+\lambda_{A}\right) e^{-\lambda_{A}}=\left(1-e^{-\lambda_{B}}\right)\left(1-e^{-\lambda_{A}}\right)$, which we can transform to $e^{-\lambda_{B}}\left(1-e^{-\lambda_{A}}\right)=\lambda_{A} e^{-\lambda_{A}}$ and further to $\lambda_{B}=\ln \left(\frac{1-e^{-\lambda_{A}}}{\lambda_{A} e^{-\lambda_{A}}}\right)$.

From equation $(i)$ we have $\frac{\partial \lambda_{B}}{\partial \lambda_{A}}=-\frac{\beta(1-\beta) \lambda_{U}^{2}}{\left[\lambda_{A}-(1-\beta) \lambda_{U}\right]^{2}}$, which is negative and defined as long as $\lambda_{A} \neq$ $(1-\beta) \lambda_{U}$. In addition, $\frac{\partial^{2} \lambda_{B}}{\left(\partial \lambda_{A}\right)^{2}}=\frac{2 \beta \lambda_{U}^{2}(1-\beta)}{\left[\lambda_{A}-(1-\beta) \lambda_{U}\right]^{3}}$. Hence, $\frac{\partial^{2} \lambda_{B}}{\left(\partial \lambda_{A}\right)^{2}}>0$ if $\lambda_{A}>(1-\beta) \lambda_{U}$ and $\frac{\partial^{2} \lambda_{B}}{\left(\partial \lambda_{A}\right)^{2}}<$ 0 if $\lambda_{A}<(1-\beta) \lambda_{U}$. Second, considering equation (ii), we can derive the following: $\frac{\partial \lambda_{B}}{\partial \lambda_{A}}=$ $\frac{\lambda_{A}-1+e^{-\lambda_{A}}}{\left(1-e^{-\lambda_{A}}\right) \lambda_{A}}>0$. Equation (ii) is positive for all values of $\lambda_{A} \geq 0$ and equation (i) is positive for $\lambda_{A}>(1-\beta) \lambda_{U}$. Note that $\lambda_{A}>(1-\beta) \lambda_{U}$ is equivalent to $N_{A}<N$ which must hold since $\beta \in(0,1)$. Hence, there is a unique solution for $\lambda_{A}, \lambda_{B}$ where both are greater than zero. This solution is illustrated in figure 1.

Note that, if $N=N_{A}+N_{B}$ increases, then the curve illustrating $\lambda_{B}=\frac{\beta \lambda_{U} \lambda_{A}}{\lambda_{A}-(1-\beta) \lambda_{U}}$ in figure 1 shifts downwards (which follows from: $\frac{\partial \lambda_{B}}{\partial N}=\frac{\partial \lambda_{U}}{\partial N} \frac{\beta \lambda_{A}^{2}}{\left[\lambda_{A}-(1-\beta) \lambda_{U}\right]^{2}}<0$ ). Thus, if $N$ increases, the equilibrium levels of both $\lambda_{A}$ and $\lambda_{B}$ decrease. Similarly, from equation $(i)$ we have $\frac{\partial \lambda_{B}}{\partial \beta}>0$ and that $\frac{\partial \lambda_{B}}{\partial \lambda_{U}}>0$, so that equation (i) shifts up and both $\lambda_{A}, \lambda_{B}$ are increasing in $\beta$ and in $\lambda_{U}$.

Lemma 11. In any symmetric SPMCE where $N_{0}<\beta N$ non-discriminatory firms coexist with $N_{D}=$ $N-N_{0}$ discriminatory firms, all of the label-blind firms post the same bonus, $b_{0 B}>b_{D B}$, and attract only B-label applicants. Hence, $N_{0 B}=N_{0}, N_{0 A}=0$ and, therefore, $S_{D A}=S_{A}$ and $N_{D A}>0$.

Proof. We start by showing that $N_{D A}, N_{D B}, N_{0 A}$, and $N_{0 B}$ cannot all simultaneously be positive. First, note that $N_{t k}>0$ in equilibrium if and only if they attract some skilled workers so that $S_{t k}>0$, therefore, $\lambda_{t k}$ would be strictly positive and finite. Second, note that if $N_{t k}>0$ then any posted bonus by the non-discriminatory firms must leave label $k$ applicants indifferent between the non-discriminating and the discriminating firms in equilibrium. For the $A$-label applicants this indifference implies $V_{0 A}=V_{D A}=\pi_{0} e^{-\lambda_{D A}}$. For the $B$-label applicants this indifference implies $V_{0 B}=V_{D B}=\pi_{0} \frac{1-e^{-\lambda_{D B}}}{\lambda_{D B}} e^{-\lambda_{D A}}$. Third, note that if both $N_{0 B}>0$ and $N_{0 A}>0$, then applicants must be indifferent between either group of label-blind firms. Putting $V_{0 A}=V_{0 B}$ and using the above relationships implies that $\pi_{0} e^{-\lambda_{D A}}=\pi_{0} \frac{1-e^{-\lambda_{D B}}}{\lambda_{D B}} e^{-\lambda_{D A}}$ or $1=\frac{1-e^{-\lambda_{D B}}}{\lambda_{D B}}$, which is impossible given that $1-e^{-\lambda_{D B}}<\lambda_{D B}$ for any $\lambda_{D B} \in(0, \infty)$. 
We now show that $N_{0 B}>0=N_{0 A}$. To see this point, note that the discriminatory firms that attract $B$-label applicants maximize expected profits subject to the constraint that the bonus for $B$-labels is no larger than the expected bonus of the A-labels. This constraint arises because an $A$-label applicant would always be hired instead of a $B$-label at any discriminatory firm. A label-blind firm does not face this constraint and because the derivative of expected profits with respect to the bonus is positive at $b_{O B}=V_{D A}(\mathbf{b})<b_{D A}$, the non-discriminatory firms can increase profits by offering a higher bonus, $b_{0 B}>b_{D B}$, to $B$-label applicants. On the other hand, when attracting $A$-label applicants, the bonus $b_{D A}$ is profit maximizing. Hence, given that all discriminatory firms earn the same profits, that the non-discriminatory firms cannot earn higher profits than the discriminatory firms if they attract $A$-labels, that they can earn higher profits if they attract $B$-labels, and that $N_{0}<\beta N<N_{B}$ (because $\lambda_{B}=\frac{\beta S}{N_{B}}<\frac{S}{N}=\lambda_{U}$ ), we must have $N_{0 B}=N_{0}>0=N_{0 A}$. Furthermore, because these $N_{0}=N_{0 B}$ firms are identical and cannot coordinate their actions we have that they all choose the same $b_{0 B}>b_{D B}$. Finally, given that $N_{0 A}=0$ and that $S_{A}>0$ it must be the case that $N_{D A}>0$.

Proposition 12. There exists a unique symmetric SPMCE with $N_{0}<\beta N$ non-discriminating firms and $N_{D}=N-N_{0}$ discriminating firms. In this equilibrium $0=\lambda_{0 A}, 0<\lambda_{D B}<\lambda_{B}, 0<\lambda_{D A}<\lambda_{A}$, $\lambda_{D B}<\lambda_{0 B}$, and $E\left(\pi_{0}^{n e t}\right)>E\left(\pi_{D A}^{n e t}\right)=E\left(\pi_{D B}^{n e t}\right)$.

Proof. The equilibrium is defined as follows. The expected profits of the discriminatory firms must be equal so that

$$
E\left(\pi_{D A}^{n e t}\right)=\left[1-\left(1+\lambda_{D A}\right) e^{-\lambda_{D A}}\right] \pi_{0}=\left(1-e^{-\lambda_{D B}}\right)\left(1-e^{-\lambda_{D A}}\right) \pi_{0}=E\left(\pi_{D B}^{n e t}\right) .
$$

If $N_{D B}=0$, then equation (20) would become $\left[1-\left(1+\lambda_{D A}\right) e^{-\lambda_{D A}}\right] \pi_{0}<\left(1-e^{-\lambda_{D A}}\right) \pi_{0}$ so that a single discriminatory firm could increase its expected profits by the choice of a hiring probability (and bonus) that would attract a $B$-label.

Note that equation (20) can be transformed to

$$
\lambda_{D B}=\ln \left(\frac{1-e^{-\lambda_{D A}}}{\lambda_{D A} e^{-\lambda_{D A}}}\right)
$$

which is comparable to equation (ii) in proposition 4. Next, using the expressions $\beta_{D}=\frac{S_{D B}}{S_{D A}+S_{D B}}$ and $\lambda_{D}=\frac{S_{D A}+S_{D B}}{N_{D A}+N_{D B}}$, an equation similar to equation $(i)$ in proposition 4 can be derived as: 


$$
\lambda_{D B}=\frac{\beta_{D} \lambda_{D} \lambda_{D A}}{\lambda_{D A}-\left(1-\beta_{D}\right) \lambda_{D}}
$$

In addition, the $B$-label applicants must be indifferent between applying to a non-discriminatory and a discriminatory firm:

$$
V_{0 B}=b_{0 B} \frac{1-e^{-\lambda_{0 B}}}{\lambda_{0 B}}=\frac{1-e^{-\lambda_{D B}}}{\lambda_{D B}} e^{-\lambda_{D A}} \pi_{0}=V_{D B} .
$$

From lemma 11 we know that $b_{0 B}>e^{-\lambda_{D A}} \pi_{0}=b_{D B}$ and because $h(\lambda)$ is declining in $\lambda$, it is, therefore, seen that $\lambda_{O B}>\lambda_{D B}$. From lemma 11 we also know that the label-blind firms do not face the same constraint as the discriminatory firms, and by increasing $b_{0 B}>b_{D B}=V_{D A}$ they have larger expected profits than the discriminatory ones so that $E\left(\pi_{0}^{n e t}\right)>E\left(\pi_{D A}^{n e t}\right)=E\left(\pi_{D B}^{n e t}\right)$.

For a given $\lambda_{0 B}$ (which is a function of the yet to be determined $S_{0 B}$ or, equivalently, $\beta_{D}$ ) the profit maximizing bonus of the non-discriminatory firms can be derived in a manner similar to that in propositions 1 and 3 as:

$$
b_{0 B}=\frac{\lambda_{0 B} \pi_{0}}{e^{\lambda_{0 B}-1}}
$$

Equations (23) and (24) can be solved for $\lambda_{0 B}$ as a function of $\lambda_{D B}$ and $\lambda_{D A}$ :

$$
\lambda_{0 B}=\ln \left(\frac{\lambda_{D B} e^{\lambda_{D A}}}{1-e^{-\lambda_{D B}}}\right) \curvearrowright
$$

Equations (21), (22), and (25) jointly determine the three variables $\lambda_{0 B}, \lambda_{D A}$ and $\lambda_{D B}$. As in proposition 4, equation (21) describes a positively sloped curve in a diagram like in figure 1, but with $\lambda_{D B}$ and $\lambda_{D A}$ on the axes. Equation (22) describes a negatively sloped and strictly convex curve in a diagram like in figure 1 as long as $\lambda_{D A}>\left(1-\beta_{D}\right) \lambda_{D}$, which is equivalent to $\frac{S_{A}}{N_{D A}}>\frac{S_{A}}{N_{D A}+N_{D B}}$, which is true. Thus, $\lambda_{D B}$ and $\lambda_{D A}$ are uniquely defined for a given level of $S_{D B}$.

To determine how $\lambda_{D B}$ and $\lambda_{D A}$ depend on $S_{D B}$, we consider equations (21) and (22). First, note that equation (21) does not depend on $S_{D B}$. Second, consider the following partial derivative from equation (22):

$$
\frac{\partial \lambda_{D B}}{\partial S_{D B}}=\frac{\frac{\partial \beta_{D}}{\partial S_{D B}}\left(\lambda_{D A}-\lambda_{D}\right) \lambda_{D}+\frac{\partial \lambda_{D}}{\partial S_{D B}} \beta_{D} \lambda_{D A}}{\left[\lambda_{D A}-\left(1-\beta_{D}\right) \lambda_{D}\right]^{2}} \lambda_{D A}
$$

which is positive since $\lambda_{D A}-\lambda_{D}>0, \frac{\partial \beta_{D}}{\partial S_{D B}}>0$ and $\frac{\partial \lambda_{D}}{\partial S_{D B}}>0$. (To see that $\lambda_{D A}-\lambda_{D}>0$, refer to equation (21) and perform the same analysis as in lemma 5.) Thus, the downward sloping curve in 
a diagram like in figure 1 shifts upward with $S_{D B}$, implying that $\lambda_{D A}$ and $\lambda_{D B}$ depend positively on $S_{D B}$.

We now show that $S_{D B}$ is uniquely defined by equation (25). Considering that $\lambda_{0 B}=\frac{S_{0 B}}{N_{0}}$, we can rewrite equation (25) as follows: $\frac{S_{B}-S_{D B}}{N_{0}}=\ln \left(\frac{\lambda_{D B} e^{\lambda} D A}{1-e^{-\lambda} D B}\right)$. Thus, the left hand side of equation (25) depends negatively on $S_{D B}$, while the right hand side of equation (25) depends positively on $S_{D B}$ :

$$
\frac{\partial}{\partial S_{D B}}\left(\ln \left(\frac{\lambda_{D B} e^{\lambda_{D A}}}{1-e^{-\lambda_{D B}}}\right)\right)=\frac{\left[1-e^{-\lambda_{D B}}\left(1+\lambda_{D B}\right)\right] \frac{\partial \lambda_{D B}}{\partial S_{D B}}+\lambda_{D B}\left(1-e^{-\lambda_{D B}}\right) \frac{\partial \lambda_{D A}}{\partial S_{D B}}}{\lambda_{D B}\left(1-e^{-\lambda_{D B}}\right)}>0 .
$$

Thus, equation (25) defines a unique value of $S_{D B}$.

The number of successful matches can then be expressed as: $M_{0 B}=S_{0 B} \frac{1-e^{-\lambda_{0 B}}}{\lambda_{0 B}}, M_{D A}=S_{A} \frac{1-e^{-\lambda_{D A}}}{\lambda_{D A}}$ and $M_{D B}=S_{D B} \frac{1-e^{-\lambda_{D B}}}{\lambda_{D B}}=\left(S_{B}-N_{0} \lambda_{0 B}\right) \frac{1-e^{-\lambda_{D B}}}{\lambda_{D B}}$. Given $M_{0}=M_{D A}+M_{D B}+M_{0 B}$ we can then solve for $I=L-S+\left[V_{D A}+\left(1-\frac{M_{D A}}{S_{A}}\right)\right] S_{A}+\left[V_{D B}+\left(1-\frac{M_{D B}}{S_{D B}}\right)\right] S_{D B}+\left[V_{0 B}+\left(1-\frac{M_{0 B}}{S_{0 B}}\right)\right] S_{0 B}$ $+M_{D A}\left(\pi_{0}-b_{D A}\right)+M_{D B}\left(\pi_{0}-b_{D B}\right)+M_{0 B}\left(\pi_{0}-b_{0 B}\right)=L+M_{0}\left(\pi_{0}-1\right)$, which in turn yields $q_{0}=$ $\alpha \frac{\sigma-1}{\sigma-\alpha}\left[\frac{L}{M_{0}}-(1+f)\right]$ and $\pi_{0}=\frac{1}{\sigma-\alpha}\left(\alpha\left[\frac{L}{M_{0}}-1\right]-\sigma f\right)$, which the allows us to solve for $b_{0 B}, b_{D A}$, $b_{D B}$ and the corresponding expected bonuses.

We now show that $\lambda_{D A}<\lambda_{A}$. To see this fact, suppose instead that $\lambda_{D A} \geq \lambda_{A}$, which implies that $N_{D A} \leq N_{A}$ (because $S_{A}$ cannot decrease). But then $N_{D B} \geq N_{B}$ and, therefore, $\lambda_{D B}<\lambda_{B}$ so that $E\left(\pi_{D A}^{n e t}\right)>E\left(\pi_{D B}^{n e t}\right)$ which does not satisfy equation (20). Hence, $\lambda_{D A}<\lambda_{A}$. Finally, to see that $\lambda_{D B}<\lambda_{B}$, note from equation (22) that $\lambda_{D B}$ is increasing in $\beta_{D}$ and in $\lambda_{D}$. This result is similar to that in proposition 4 . Hence, because some of the $B$-labels apply to the non-discriminatory firms, we must have $\beta_{D}<\beta$ and, because $S_{D A}=S_{A}$, we must also have $\lambda_{D}<\lambda_{U}$. Hence, $\lambda_{D B}<\lambda_{B}$. 


\section{References}

[1] Arrow, K. J., 1972. "Some Mathematical Models of Race in the Labor Market," in: Pascal, A. (ed.): Racial Discrimination in Economic Life, D.C. Health, Lexington, MA, pp. 187-203.

[2] Becker, G. S., 1957. “The Economics of Discrimination," University of Chicago Press, Chicago, IL.

[3] Black, D. A., 1995. “Discrimination in an Equilibrium Search Model," Journal of Labor Economics, vol. 13(2), pp. 309-333.

[4] Bloom, N., and Van Reenen, J., 2007. “Measuring and Explaining Management Practices Across Firms and Countries," Quarterly Journal of Economics, vol. 122(4), pp. 1351-1408.

[5] Cavalcanti, T., and Tavares, J., 2016. “The Output Cost of Gender Discrimination: A ModelBased Macroeconomic Estimate," Economic Journal, vol. 126(590), pp. 109-134.

[6] Cuberes, D. and Teignier, M., 2014. “Gender Inequality and Economic Growth: A Critical Review," Journal of International Development, vol. 26(2), pp. 260-276.

[7] Davidson, C., Martin, L., and Matusz, S., 1999. "Trade and search generated unemployment," Journal of International Economics, vol. 48(2), pp. 271-299.

[8] Davidson, C., Matusz, S., and Shevchenko, A., 2008. "Globalization and firm level adjustment with imperfect labor markets," Journal of International Economics, vol. 75(2), pp. 295-309.

[9] Dixit, A., and Stiglitz, J., 1977. "Monopolistic Competition and Optimum Product Diversity," American Economic Review, vol. 67(3), pp. 297-308.

[10] Esteve-Volart, B., 2009. “Gender Discrimination and Growth: Theory and Evidence from India," manuscript.

[11] Fang, H., and Moro, A. 2010. "Theories of Statistical Discrimination and Affirmative Action: A Survey," in: Benhabib, J., Bisin, A., and Jackson, M. (eds.): Handbook of Social Economics, Vol. IA, Elsevier, Amsterdam et al., pp. 133-200.

[12] Galor, O., and Weil, D., 1996. "The Gender Gap, Fertility, and Growth," American Economic Review, vol. 85(3), pp. 374-387. 
[13] Hsieh, C., Hurst, E., Jones, C., and Klenow, P., 2013. “The Allocation of Talent and U.S. Economic Growth," NBER working paper no. 18693.

[14] Lagerlöf, N.-P., 2003. “Gender Equality and Long Run Growth,” Journal of Economic Growth, vol. 8(4), pp. 403-426.

[15] Grossman, G., Helpman, E., and Kircher, P., 2013. “Matching and Sorting in a Global Economy," NBER working paper no. 19513.

[16] Helpman, E., and Itskhoki, O., 2010. "Labour Market Rigidities, Trade and Unemployment," Review of Economic Studies, vol. 77(3), pp. 1100-1137.

[17] Helpman, E., Itskhoki, O., and Redding, S., 2010. “Inequality and Unemployment in a Global Economy," Econometrica, vol. 78(4), pp. 1239-1283.

[18] Lang, K., and Lehman, J., 2012. "Racial Discrimination in the Labor Market," Journal of Economic Literature, vol. 50(4), pp. 959-1006.

[19] Lang, K., Manove, M., and Dickens, W., 2005. “Racial Discrimination in Labor Markets with Posted Wage Offers," American Economic Review, vol. 95(4), pp. 1327-1340.

[20] Murphy, K., 2014. "How Gary Becker Saw the Scourge of Discrimination," Capital Ideas, Winter 2014.

[21] Ranjan, P., 2013. “Offshoring, Unemployment, and Wages: The Role of Labor Market Institutions," Journal of International Economics, vol. 89(1), pp. 172-186.

[22] Rosen, A., 1997. “An Equilibrium Search-Matching Model of Discrimination,” European Economic Review, vol. 41(8), pp. 1589-1613.

[23] Rosen, A., 2003. "Search, Bargaining, and Employer Discrimination," Journal of Labor Economics, vol. 21(4), pp. 807-830. 